\title{
Pivotal Roles for Ribonucleases in Streptococcus pneumoniae Pathogenesis
}

\author{
Dhriti Sinha, ${ }^{\text {a,b }}$ Jacob P. Frick, ${ }^{a}$ Kristen Clemons, $^{\text {a }}$ (D) Malcolm E. Winkler, ${ }^{\text {b }}$ (D) Nicholas R. De Lay ${ }^{a, c}$ \\ aDepartment of Microbiology and Molecular Genetics, McGovern Medical School, University of Texas Health Science Center, Houston, Texas, USA \\ bDepartment of Biology, Indiana University Bloomington, Bloomington, Indiana, USA \\ cMD Anderson Cancer Center UTHealth Graduate School of Biomedical Sciences, University of Texas Health Science Center, Houston, Texas, USA
}

ABSTRACT RNases perform indispensable functions in regulating gene expression in many bacterial pathogens by processing and/or degrading RNAs. Despite the pivotal role of RNases in regulating bacterial virulence factors, the functions of RNases have not yet been studied in the major human respiratory pathogen Streptococcus pneumoniae (pneumococcus). Here, we sought to determine the impact of two conserved RNases, the endoribonuclease RNase $\mathrm{Y}$ and exoribonuclease polynucleotide phosphorylase (PNPase), on the physiology and virulence of $S$. pneumoniae serotype 2 strain D39. We report that RNase $Y$ and PNPase are essential for pneumococcal pathogenesis, as both deletion mutants showed strong attenuation of virulence in murine models of invasive pneumonia. Genome-wide transcriptomic analysis revealed that the abundances of nearly 200 mRNA transcripts were significantly increased, whereas those of several pneumococcal small regulatory RNAs (sRNAs), including the Ccn (CiaR-controlled noncoding RNA) sRNAs, were altered in the $\Delta r n y$ mutant relative to the wild-type strain. Additionally, lack of RNase $Y$ resulted in pleiotropic phenotypes that included defects in pneumococcal cell morphology and growth in vitro. In contrast, $\Delta p n p$ mutants showed no growth defect in vitro but differentially expressed a total of 40 transcripts, including the tryptophan biosynthesis operon genes and numerous $5^{\prime}$ cis-acting regulatory RNAs, a majority of which were previously shown to impact pneumococcal disease progression in mice using the serotype 4 strain TIGR4. Together, our data suggest that RNase $Y$ exerts a global impact on pneumococcal physiology, while PNPase mediates virulence phenotypes, likely through sRNA regulation.

IMPORTANCE Streptococcus pneumoniae is a notorious human pathogen that adapts to conditions in distinct host tissues and responds to host cell interactions by adjusting gene expression. RNases are key players that modulate gene expression by mediating the turnover of regulatory and protein-coding transcripts. Here, we characterized two highly conserved RNases, RNase $\mathrm{Y}$ and PNPase, and evaluated their impact on the S. pneumoniae transcriptome for the first time. We show that PNPase influences the levels of a narrow set of mRNAs but a large number of regulatory RNAs primarily implicated in virulence control, whereas RNase $Y$ has a more sweeping effect on gene expression, altering levels of transcripts involved in diverse cellular processes, including cell division, metabolism, stress response, and virulence. This study further reveals that RNase $\mathrm{Y}$ regulates expression of genes governing competence by mediating the turnover of CiaR-controlled noncoding (Ccn) sRNAs.

KEYWORDS RNase Y, polynucleotide phosphorylase, posttranscriptional regulation, small RNAs

he Gram-positive bacterium Streptococcus pneumoniae (pneumococcus) is a common colonizer of the human nasopharynx, where it can remain as a commensal. However, specific signals, including host viral infection and environmental and nutritional
Citation Sinha D, Frick JP, Clemons K, Winkler ME, De Lay NR. 2021. Pivotal roles for ribonucleases in Streptococcus pneumoniae pathogenesis. mBio 12:e2385-21. https://doi .org/10.1128/mBio.02385-21

Editor Gisela Storz, National Institute of Child Health and Human Development (NICHD) Copyright $\odot 2021$ Sinha et al. This is an openaccess article distributed under the terms of the Creative Commons Attribution 4.0 International license.

Address correspondence to Malcolm E. Winkler, winklerm@indiana.edu, or Nicholas R. De Lay, nicholas.r.delay@uth.tmc.edu.

This article is a direct contribution from Malcolm E. Winkler, a Fellow of the American Academy of Microbiology, who arranged for and secured reviews by Joerg Vogel, University of Würzburg, and Jan-Willem Veening, University of Lausanne.

Received 12 August 2021

Accepted 19 August 2021

Published 21 September 2021 
stress, can stimulate S. pneumoniae to disperse into other host tissues $(1,2)$, including the lungs, blood, and brain, and dissemination of pneumococcus into these tissues leads to pneumonia, sepsis, and meningitis, respectively. Pneumococcal infections result in over 1 million deaths annually worldwide (3). S. pneumoniae has been shown in murine infection models to have distinct gene expression profiles depending on whether it resides in the blood, brain, nasopharynx, or lungs $(4,5)$, indicating that it has to adapt to the different conditions in these tissues to survive. Furthermore, pneumococcus also rapidly reprograms its gene expression pattern upon exposure to host cells, such as macrophages (6) and lung epithelial cells $(7,8)$. To rapidly adapt to changes in their environment, bacteria not only need to modulate the transcription of particular genes but also must turn over existing small regulatory RNAs (sRNAs) or mRNAs that encode proteins detrimental under the new set of conditions. RNases control the steady-state levels and turnover of various classes of RNAs $(9,10)$. In the model Gram-positive bacterium Bacillus subtilis, the primary RNase responsible for initiating RNA decay was shown to be RNase $Y$ (11). Depletion of this RNase from $B$. subtilis impacted expression of $\sim 20 \%$ of all open reading frames in its genome (12) and led to a 2-fold increase in the half-life of bulk mRNA (11).

RNase $Y$ is the functional but evolutionarily distinct equivalent of endoribonuclease RNase $\mathrm{E}$ of Gram-negative bacteria. RNase $\mathrm{Y}$ consists of an N-terminal transmembrane domain followed by a coiled-coil domain, an RNA-binding KH domain, a catalytic HD domain, and a C-terminal domain (12). Like RNase E, RNase $Y$ associates with the membrane (13) and also serves as the organizing component of the RNA degradosome, the central RNA-degrading machine in bacteria (12). RNase $Y$ forms this complex by interacting with the RNA helicase CshA, the RNases $\mathrm{J} 1$ and $\mathrm{J} 2$, the glycolytic enzymes phosphofructokinase and enolase, and the exoribonuclease PNPase $(12,14)$. The dual-function RNases J1/J2 exhibit both endonucleolytic and 5'-to-3' exoribonucleolytic activities and are unique to Gram-positive bacteria (15). In Bacillus subtilis and Streptococcus pyogenes, the decay intermediates resulting from endonucleolytic cleavage are primarily cleared by PNPase, which functions as the major $3^{\prime}$-to- $5^{\prime}$ exoribonuclease $(16,17)$. PNPase has also been shown to significantly impact global mRNA turnover under cold stress in $B$. subtilis and Staphylococcus aureus, similar to what has been demonstrated in Escherichia coli $(18,19)$.

Very recent transcriptome sequencing (RNA-seq) studies in S. pyogenes have uncovered the RNA targetomes of both RNase $Y$ and PNPase and further demonstrated that these two proteins work in concert to regulate 5 '-regulatory RNA turnover and the stability of polycistronic mRNAs (20). These results are consistent with the previously implicated role of RNase $\mathrm{Y}$ in mediating decay of $5^{\prime}$ cis-acting regulatory RNAs ( $S$-adenosylmethionine, T-box, and riboflavin riboswitches) in S. aureus and B. subtilis $(11,21$, 22). Interestingly, results of a recent study that globally examined protein-RNA associations in S. pneumoniae via gradient profiling by sequencing (Grad-seq) indicate that PNPase interacts with several small RNAs in vivo (23). However, compared to those in Gram-negative bacteria, the detailed mechanisms by which major RNases in Gram-positive organisms, such as RNase $Y$ and PNPase, impact sRNA-dependent regulation and trans-acting sRNA levels remain largely unknown; however, there has been some evidence for RNase Y-dependent turnover of sRNAs (e.g., RsaA in S. aureus and RoxS in B. subtilis [24]). Independent studies have further indicated an indirect role of RNase $Y$ in regulating the abundance of two other trans-acting sRNAs, VR-RNA and FasX, in the important Gram-positive pathogens Clostridium perfringens and S. pyogenes, respectively $(25,26)$. The extents to which RNase $Y$ orthologs from different species contribute to growth and RNA decay vary considerably (22). These findings further emphasize that various Gram-positive organisms, including pathogens, may employ different mechanistic strategies to mediate RNA decay and processing.

In spite of the crucial roles of RNases in impacting bacterial stress response by altering gene expression, we do not know about the functions of major pneumococcal RNases. In the present work, we report characterization of two conserved RNases, RNase $\mathrm{Y}$ and PNPase, in S. pneumoniae serotype 2 strain D39. We demonstrate that 
RNase $Y$ functions as a broadly pleiotropic regulator whose absence significantly impacts the pneumococcal mRNA transcriptome, growth, virulence, and stability and function of conserved pneumococcal Ccn (CiaR-controlled noncoding RNA) sRNAs. In contrast, PNPase impacts the abundance of several important transcripts, including riboswitches that were previously implicated in pneumococcal virulence control. The absence of PNPase consistently resulted in a strong virulence defect in vivo while displaying no obvious phenotypes in vitro. Together, our work has uncovered for the first time the crucial roles of two wellconserved RNases in regulating pneumococcal physiology and virulence.

\section{RESULTS}

RNase $\mathrm{Y}$ is required for normal pneumococcal growth and cell morphology. Prior studies showed that deletion of rny, the gene encoding RNase $Y$, from $B$. subtilis and $C$. perfringens caused a drastic reduction in growth, but the effect of removal of this gene on S. pyogenes and S. aureus growth was modest (25, 27-29). However, deletion of pnp led to a cold-sensitive phenotype in $B$. subtilis, similar to what was observed for Escherichia coli $(30,31)$. Therefore, we assessed the effects of clean deletion in rny or pnp (Table S1) on pneumococcal growth at both optimal $\left(37^{\circ} \mathrm{C}\right)$ and lower $\left(32^{\circ} \mathrm{C}\right)$ temperatures. We found that at $37^{\circ} \mathrm{C}$ in brain heart infusion (BHI) broth, the $\Delta r n y$ mutant exhibited a significant reduction in growth rate and yield compared to the wildtype (WT) strain (Fig. 1A; Table S2). The average doubling time and growth yield for the $\Delta$ rny mutant were $\sim 69 \mathrm{~min}$ and 0.37 , compared with $\sim 39 \mathrm{~min}$ and 0.96 for the WT strain. The observed growth defect of the $\Delta$ rny mutant was restored by expressing rny from a constitutive $P_{\text {mal(c) }}$ promoter at the ectopic CEP (chromosomal expression platform) locus or by repairing the mutation to the WT allele at the native locus (Fig. 1A; Fig. S1A to D; Table S2). We also observed that the growth deficiency of the $\Delta r n y$ mutant became more pronounced in 15- and 25-day-old $\mathrm{BHI}$ compared to freshly prepared ( $\leq 5$-day-old) $\mathrm{BHI}$, whereas the isogenic parental strain grew similarly in fresh and aged $\mathrm{BHI}$ (Fig. S1 to D; Table S2). In contrast, the $\Delta p n p$ mutant grew like the WT strain in $\mathrm{BHI}$ broth at $37^{\circ} \mathrm{C}$ (Fig. $1 \mathrm{~A}$; Fig. S1A to D). In contrast to E. coli and B. subtilis $(30,31)$, the pneumococcal $\Delta p n p$ mutant did not show a cold-sensitive (CS) phenotype (Fig. 1B) at $32^{\circ} \mathrm{C}$, the lowest temperature at which S. pneumoniae D39 grows well. Finally, the $\Delta r n y$ mutant was not cold sensitive, as the growth rate differences between the WT and $\Delta$ rny mutant were not significantly different at $32^{\circ} \mathrm{C}$ compared to $37^{\circ} \mathrm{C}$ (Fig. 1B; Fig. S1E to G; Table S2).

To gain insight into the growth impairment of $\Delta r n y$ mutants, we examined cells from early-exponential-phase cultures (optical density at $620 \mathrm{~nm}\left[\mathrm{OD}_{620}\right] \approx 0.1$ to 0.15 ) of the WT and $\Delta r n y$ mutant by phase-contrast microscopy. We found that the $\Delta r n y$ mutant exhibits significant morphological defects. Occasionally, $\Delta$ rny mutants formed minicells at the ends or in the middle of a chain, indicating a possible cell division defect (Fig. 1C). The abnormalities in cell morphology that we observed in the encapsulated $\Delta$ rny mutant were even more pronounced in a $\Delta c p s$ mutant lacking capsule (Fig. 1C). This observation is consistent with previous findings that capsule tends to dampen pneumococcal cell shape and division phenotypes (32). In addition, the $\Delta$ rny $\Delta c p s$ mutant formed longer chains comprising 4 to 12 cells/chain, in contrast to the WT parent, which occurred mainly as diplococci (Fig. 1C). The observed chaining effect of the $\Delta$ rny mutant was reversed by expressing rny from a constitutive $\mathrm{P}_{\text {mal(c) }}$ promoter at the ectopic CEP locus (Fig. 1C). Finally, we did not observe any morphological differences between the $\Delta p n p$ mutant and the WT parent in either the $c p s^{+}$or the $\Delta c p s$ background (Fig. 1C). We conclude that RNase $\mathrm{Y}$, but not PNPase, is required for $S$. pneumoniae D39 normal growth and cell morphology.

Lack of RNase Y or PNPase attenuates S. pneumoniae D39 pathogenesis. Lack of RNase $Y$ in $S$. pyogenes and $S$. aureus resulted in virulence attenuation $(28,33,34)$. Therefore, we determined the consequences of the rny and pnp deletions on S. pneumoniae D39 pathogenesis using a murine invasive pneumonia model (see Materials and Methods). Both the $\Delta r n y$ and $\Delta p n p$ mutants were substantially attenuated for virulence compared to the WT parent (Fig. 1D and E). Of the mice inoculated with the $\Delta p n p$ or $\Delta r n y$ 
A

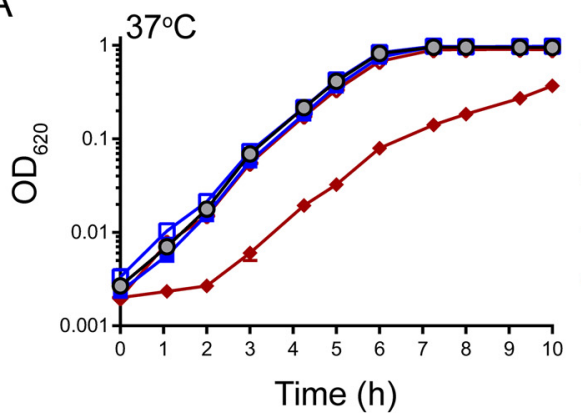

C

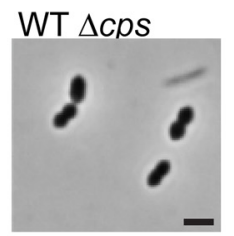

$\Delta p n p \Delta c p s$
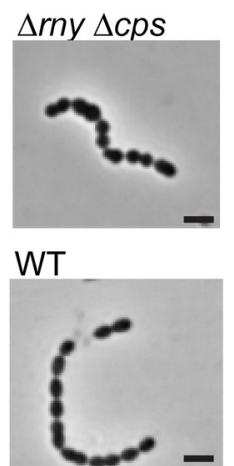

$\Delta r n y$
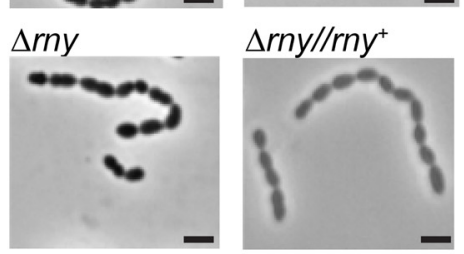

- W WT

- $\Delta p n p$

४ $\Delta p n p / / p n p^{+}$

$\rightarrow \Delta r n y$

$\diamond \Delta r n y / / r n y^{+}$
B

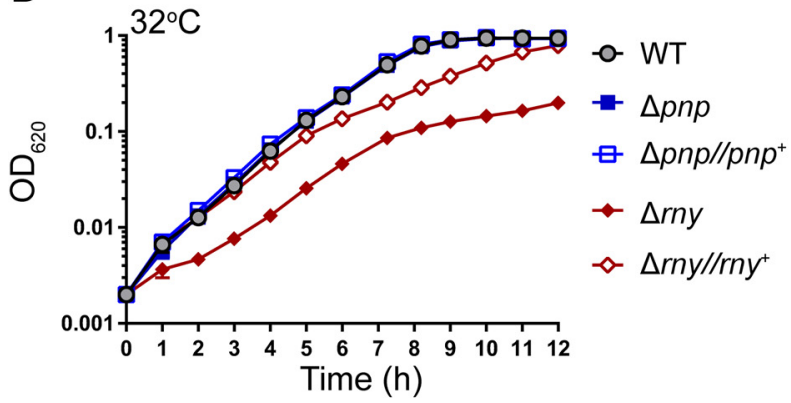

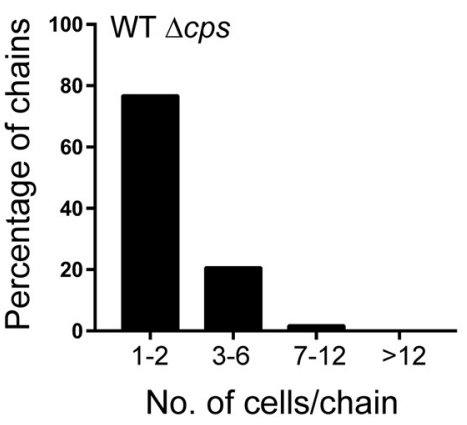

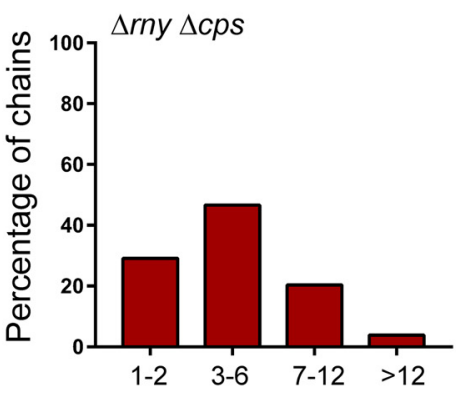

No. of cells/chain
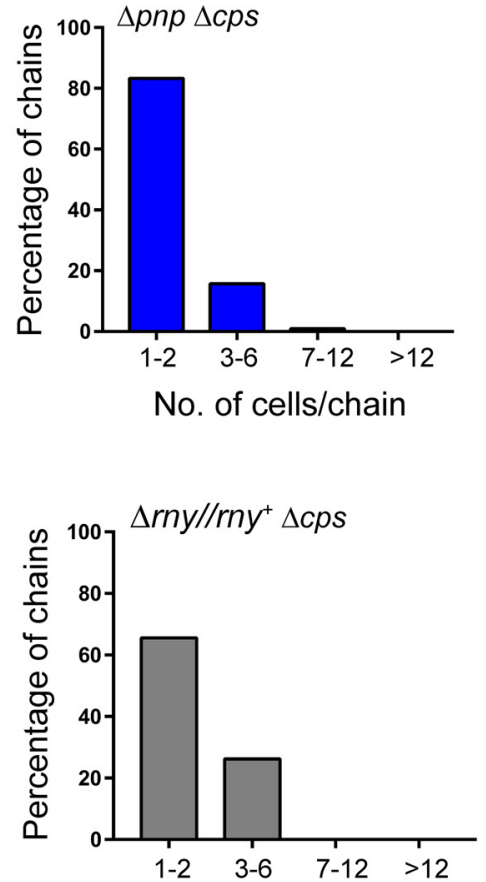

No. of cells/chain
D

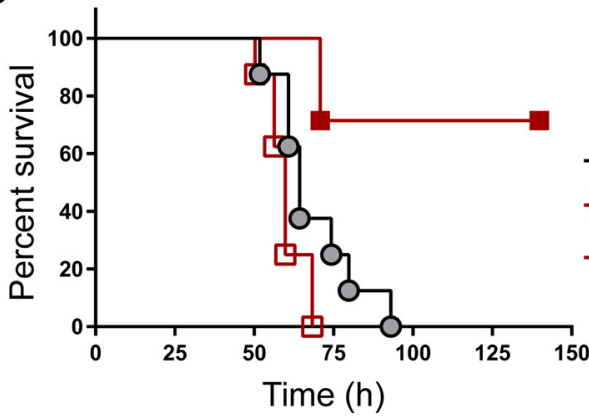

E

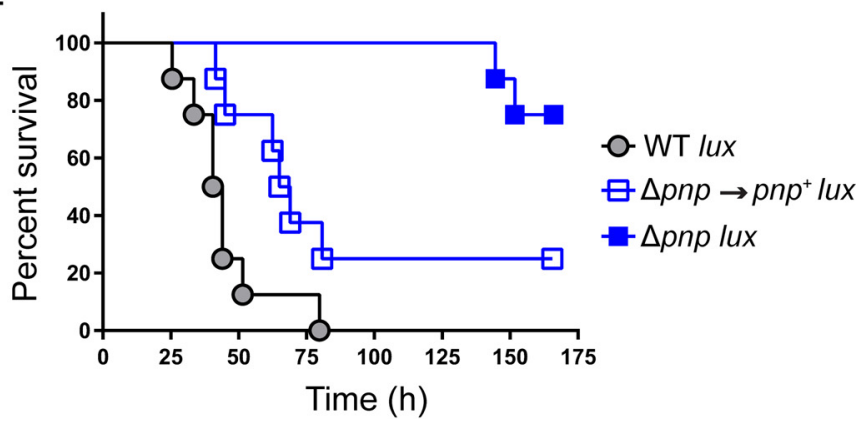

FIG 1 Phenotypes of $\Delta r n y$ and $\Delta p n p$ mutants. (A and B) Growth characteristics of the encapsulated D39 parent strain (IU1781), isogenic $\Delta r n y$ (IU4599) and $\Delta p n p$ (IU4883) strains, and complemented $\Delta$ rny//rnny (IU4834) and $\Delta p n p / / p n p^{+}$(IU5510) strains, grown statically at $37^{\circ} \mathrm{C}$ and at $32^{\circ} \mathrm{C}$ in 5 -day-old $\mathrm{BHI}$ broth in an atmosphere of $5 \% \mathrm{CO}_{2}$. Growth curves represent data from three independent replicates for each strain at $37^{\circ} \mathrm{C}$ or $32^{\circ} \mathrm{C}$. Average growth rates and growth yields are listed in Table S2. (C) Representative phase-contrast images of the D39 wild-type strain (WT; IU1781), its derived $\Delta c p s$ (IU1824), $\Delta$ rny (NRD10092), $\Delta p n p$ (IU4883), $\Delta c p s \Delta r n y$ (NRD10109), and $\Delta c p s \Delta p n p$ (NRD10108) mutants, and $\Delta$ rny//rny $+($ NRD10388) and $\Delta c p s \quad \Delta r n y / /$ rny + (NRD10389) complemented strains in early exponential growth phase. Distributions of chain lengths were based on 100 to 200 chains from at least two independent cultures of each strain. Bars, $2 \mu \mathrm{m}$. ( $D$ and E) Survival curve analysis showing disease progression in an invasive murine model of pneumonia. ICR male mice were inoculated intranasally with $\sim 10^{7}$ CFU in 50- $\mu$ l inocula of the D39 parent expressing a lux luminescence cassette (D39 
mutant, $75 \%$ and $87 \%$, respectively, survived the course of the experiment ( $\sim 170 \mathrm{~h})$, whereas the median survival time for the WT parent strain ranged from $42 \mathrm{~h}$ to $64 \mathrm{~h}$ (Fig. 1D and E; Fig. S2A). To determine if the attenuated virulence observed in each case was correlated with loss of rny or pnp function, we repaired $\Delta r n y$ or $\Delta p n p$ back to the $r n y^{+}$ or $p n p^{+}$allele, respectively, by allelic exchange (see Materials and Methods). The $r n y^{+}$and $p_{n}{ }^{+}$repaired strains displayed median survival times of $60 \mathrm{~h}$ and $67 \mathrm{~h}$, respectively, indicative of full virulence. Taking these results together, we conclude that both RNase $Y$ and PNPase contribute to pneumococcal pathogenesis.

RNase $Y$ and PNPase impact the pneumococcal mRNA transcriptome differently. To identify target transcripts of RNase $\mathrm{Y}$ or PNPase that influence pneumococcal physiology, next, we compared the genome-wide transcriptome profiles of $\Delta r n y$ or $\Delta p n p$ mutant relative to the WT parent grown in matched batches of $\mathrm{BHI}$ broth at $37^{\circ} \mathrm{C}$ in an atmosphere of $5 \% \mathrm{CO}_{2}$ using mRNA-sequencing (mRNA-seq) analysis (see Materials and Methods). mRNA-seq of the $\Delta$ rny mutant revealed that 185 transcripts were significantly upregulated compared to the WT parent strain, using a cutoff of a $>1.8$-fold change and a $P$ value adjusted for multiple testing $\left(P_{\text {adj }}\right)$ of $<0.05$. In contrast, only 28 genes were significantly downregulated in the $\Delta r n y$ mutant compared to the WT strain (Table 1; Fig. 2A). The upregulated transcripts encode proteins that are involved in diverse cellular functions, including translation; transcription; transport and metabolism of carbohydrates, amino acids, nucleotides, coenzymes, and inorganic ions; cell wall and envelope biogenesis; and stress response (Table 1). In particular, several transcripts that were upregulated in the $\Delta$ rny mutant are under the regulatory control of the WaIRK, LiaFSR, PnpRS, or CiaRH two-component system (TCS) (Table 1). Notably, relative transcript abundance for genes encoding important cell division and cell wall proteins, including mapZ, cozE, gpsB, lytB, licB, licC, licA, tarl, tarJ, spd_0703, and spd_0104, were increased by $\sim 2-5$-fold in the $\Delta r n y$ strain. Lack of RNase $Y$ also increased the relative expression of genes involved in stress response (clpL, 9-fold; dnaK, 6-fold; dnaJ, 3-fold; $h p t X$, 2-fold) and pavB ( $\sim 2$-fold), which encodes a fibronectin-binding protein involved in pneumococcal virulence.

Deletion of $p n p$ had substantially less impact on relative mRNA transcript amounts, with significant changes in abundance of only 20 transcripts (Table 2; Fig. 2C). Interestingly, a majority of mRNA transcripts that were differentially regulated in the $\Delta p n p$ mutant were shown by a previous transposon insertion sequencing (Tn-seq) screen of serotype 4 strain TIGR4 to be important for colonization of the nasopharynx and/or infection of the lungs in murine infection models (35) (Table 2). In particular, the relative abundance of transcripts corresponding to the tryptophan biosynthesis operon (trpABCDEFG), including the upstream gene spd_1604, were maximally downregulated by $\sim 3$ - to 4-fold. In addition, the relative transcript amount of alaS, which encodes alanyl-tRNA-synthetase, was downregulated by $\sim 2$-fold in the $\Delta p n p$ mutant compared to the WT strain (Table 2; Fig. 2C).

Results from mRNA-seq analyses were confirmed by reverse transcriptase droplet digital PCR (RT-ddPCR) as described in Materials and Methods. Consistent with the RNA-seq results, the relative transcript amounts of mapZ ( $\sim 2$-fold), spd_0703 ( $\sim 3$-fold), clpL ( $\sim$-fold), and dnaK ( $\sim 2$-fold) increased in the $\Delta$ rny mutant compared to WT strain (Fig. 2B). In the $\triangle p n p$ mutant, RT-ddPCR showed that the relative transcript amounts of spd_1604-trpD-trpA-trpE and alaS decreased by $\sim 4$-fold and 2.4-fold, respectively, whereas the relative amount of spd_0437 (ribU) increased by $\sim 6$-fold (Fig. 2D), again consistent with the RNA-seq results. Together, these data confirm the relative changes in steady-state mRNA transcript amounts caused by lack of RNase $\mathrm{Y}$ or PNPase in $S$. pneumoniae.

FIG 1 Legend (Continued)

Tn4001 luxABCDE [IU1918]) or isogenic mutants ( $\Delta$ rny Tn4001 luxABCDE [IU6838]; $\triangle p n p$ Tn4001 luxABCDE [IU6622]; rny ${ }^{+}$Tn4001 luxABCDE [IU7152]; and $p_{n}{ }^{+}$Tn4001 luxABCDE [IU7154]). Eight animals were infected per strain, and disease progression was followed in real time by survival curve analysis (see Materials and Methods). Survival curves were analyzed by Kaplan-Meier statistics and log-rank tests to determine $P$ values. 
TABLE 1 Genes showing changes in relative mRNA transcript amounts in a $\Delta$ rny mutant compared to the rny ${ }^{+}$parent strain during exponential growth in $\mathrm{BHI}$ broth $^{a}$

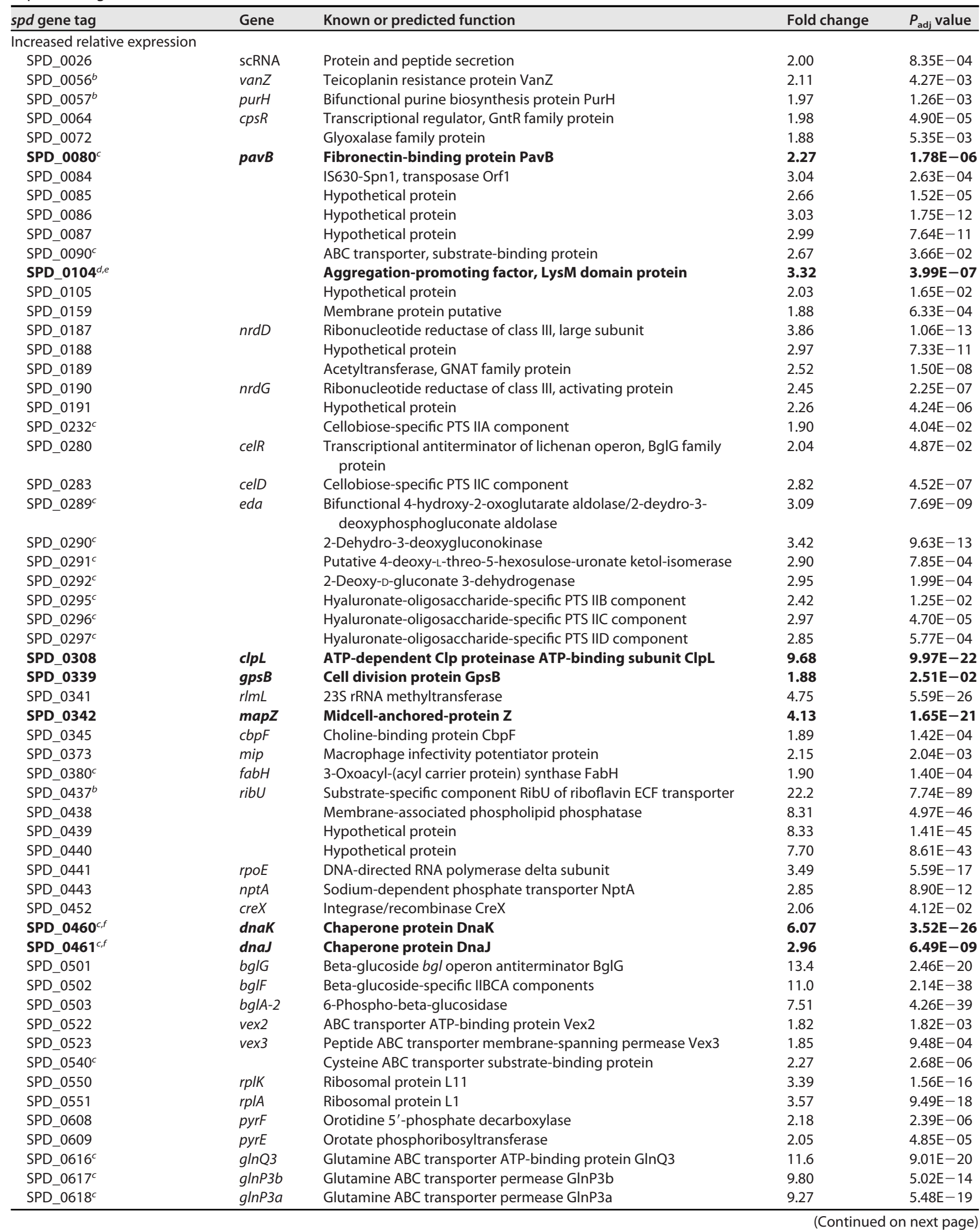


TABLE 1 (Continued)

\begin{tabular}{|c|c|c|c|c|}
\hline spd gene tag & Gene & Known or predicted function & Fold change & $P_{\text {adj }}$ value \\
\hline SPD_0627 & ykoC & $\begin{array}{l}\text { Transmembrane component YkoC of energizing module of } \\
\text { thiamin-regulated ECF transporter for } \\
\text { hydroxymethylpyrimidine }\end{array}$ & 1.82 & $8.02 \mathrm{E}-03$ \\
\hline SPD_0629 & thiW & $\begin{array}{l}\text { Substrate-specific component ThiW of putative thiazole ECF } \\
\text { transporter }\end{array}$ & 1.86 & $4.65 \mathrm{E}-03$ \\
\hline SPD_0676 & & Hypothetical protein & 2.54 & $5.46 \mathrm{E}-09$ \\
\hline SPD_0679 & $\operatorname{trmD}$ & tRNA (guanine-N1)-methyltransferase & 2.36 & $5.40 \mathrm{E}-08$ \\
\hline SPD_0680 & & Anaerobic ribonucleoside-triphosphate reductase & 2.09 & $6.79 \mathrm{E}-06$ \\
\hline SPD_0681 & & Hypothetical protein & 3.63 & $3.84 \mathrm{E}-07$ \\
\hline SPD_0683 & & Hypothetical protein & 1.87 & $1.63 \mathrm{E}-03$ \\
\hline SPD_0692 & & Hypothetical protein & 1.89 & $4.36 \mathrm{E}-04$ \\
\hline SPD_0703 ${ }^{d}$ & & Hypothetical protein & 5.18 & $1.15 \mathrm{E}-19$ \\
\hline SPD_0806 & & Hypothetical protein & 2.18 & $5.09 \mathrm{E}-04$ \\
\hline SPD_0852 & pyrDb & Dihydroorotate dehydrogenase, catalytic subunit & 1.84 & $1.85 \mathrm{E}-03$ \\
\hline SPD_0853 ${ }^{d}$ & lytB & Endo-beta- $N$-acetylglucosaminidase LytB & 1.87 & $3.88 \mathrm{E}-02$ \\
\hline SPD_0872 ${ }^{b}$ & & Membrane protein, putative & 1.84 & $1.23 \mathrm{E}-03$ \\
\hline SPD_0882 & & IS630-Spn1, transposase Orf2, truncation & 2.76 & $6.41 \mathrm{E}-08$ \\
\hline SPD_0883 & & Hypothetical protein & 3.80 & $1.58 \mathrm{E}-11$ \\
\hline SPD_0884 & & Hypothetical protein & 4.20 & $6.64 \mathrm{E}-15$ \\
\hline SPD_0898 & & Membrane protein, putative & 2.28 & $1.50 \mathrm{E}-07$ \\
\hline SPD_0913 ${ }^{g, h}$ & & Extracellular protein & 3.06 & $6.56 \mathrm{E}-04$ \\
\hline SPD_0930 & pezA & Antitoxin PezA & 2.46 & $9.80 \mathrm{E}-05$ \\
\hline SPD_0931 & pezT & Bifunctional UDP-N-acetylglucosamine kinase/zeta toxin PezT & 2.27 & $1.01 \mathrm{E}-05$ \\
\hline SPD_0932 & & Hypothetical protein & 1.90 & $4.08 \mathrm{E}-03$ \\
\hline SPD_1046 & lacG-2 & 6-Phospho- $\beta$-galactosidase & 7.18 & $1.92 \mathrm{E}-13$ \\
\hline SPD_1047c & lacE-2 & Lactose-specific PTS IIBC components & 7.64 & $1.65 \mathrm{E}-15$ \\
\hline SPD_1048c & lacF-2 & Lactose-specific PTS IIA component & 5.84 & $2.69 \mathrm{E}-15$ \\
\hline SPD_1049 & lact & Transcriptional antiterminator LacT & 4.75 & $7.81 \mathrm{E}-07$ \\
\hline SPD_1073 & & $\begin{array}{l}\text { Bifunctional O-acetylhomoserine sulfhydrylase/O- } \\
\text { succinylhomoserine sulfhydrylase }\end{array}$ & 1.88 & $2.86 \mathrm{E}-03$ \\
\hline SPD_1075 & $\operatorname{nirC}$ & Formate-nitrate transporter & 2.15 & $6.55 \mathrm{E}-06$ \\
\hline SPD_1090 & pant & $\begin{array}{l}\text { Substrate-specific component PanT of putative pantothenate ECF } \\
\text { transporter }\end{array}$ & 1.80 & $1.86 \mathrm{E}-03$ \\
\hline SPD_1123 ${ }^{g}$ & licC & Cholinephosphate cytidylyltransferase LicC & 1.88 & $2.50 E-04$ \\
\hline SPD_1124 ${ }^{g}$ & licB & Choline permease LicB & 1.92 & $1.69 E-04$ \\
\hline SPD_1125 & licA & Choline kinase LicA & 2.04 & $1.42 E-05$ \\
\hline SPD_1126 ${ }^{g}$ & tarJ & Ribulose-5-phosphate reductase & 2.09 & $7.78 \mathrm{E}-06$ \\
\hline SPD_1127 ${ }^{g}$ & tarl & Ribitol-5-phosphate cytidylyltransferase & 2.10 & $7.83 E-06$ \\
\hline SPD_1138 & hptX & Heat shock protein HtpX & 2.04 & $1.25 E-05$ \\
\hline SPD_1139 & $\operatorname{lem} A$ & LemA protein & 2.08 & $1.44 \mathrm{E}-05$ \\
\hline SPD_1148 & $r p / s$ & Ribosomal protein L19 & 6.76 & $7.46 \mathrm{E}-32$ \\
\hline SPD_1159 & & Hypothetical protein & 2.58 & $4.76 \mathrm{E}-07$ \\
\hline SPD_1160 ${ }^{f}$ & & ABC transporter ATP-binding protein & 2.68 & $3.74 E-10$ \\
\hline SPD_1161 & & Hypothetical protein & 2.36 & $2.91 \mathrm{E}-04$ \\
\hline SPD_1175 & & Hypothetical protein & 2.18 & $9.50 \mathrm{E}-05$ \\
\hline SPD_1176 & & $A B C$ transporter ATP-binding protein & 2.26 & $6.98 \mathrm{E}-06$ \\
\hline SPD_1177c & & $\mathrm{ABC}$ transporter ATP-binding/membrane spanning protein & 2.65 & $2.09 \mathrm{E}-07$ \\
\hline SPD_1178 & ptrB & Protease II & 2.75 & $7.36 \mathrm{E}-07$ \\
\hline
\end{tabular}


TABLE 1 (Continued)

\begin{tabular}{|c|c|c|c|c|}
\hline spd gene tag & Gene & Known or predicted function & Fold change & $P_{\text {adj }}$ value \\
\hline SPD_1179 & lanL & Lanthionine biosynthesis protein LanL & 3.26 & $2.40 \mathrm{E}-08$ \\
\hline SPD_1267 & & $A B C$ transporter, ATP-binding protein & 2.88 & $1.10 \mathrm{E}-02$ \\
\hline SPD_1294 & & Conserved hypothetical protein & 1.99 & $1.64 \mathrm{E}-03$ \\
\hline SPD_1295 & & Hemolysin & & $2.11 \mathrm{E}-03$ \\
\hline SPD_1296 & $p d \times 2$ & Glutamine amidotransferase, SNO family protein, putative & 2.28 & $4.89 \mathrm{E}-04$ \\
\hline SPD_1297 & $p d x 1$ & Pyridoxine biosynthesis protein & 2.18 & $2.78 \mathrm{E}-04$ \\
\hline SPD_1301 & & NADPH-dependent FMN reductase & 1.96 & $5.26 \mathrm{E}-03$ \\
\hline SPD_1302 ${ }^{b}$ & & Oxidoreductase, putative & 1.90 & $6.25 \mathrm{E}-04$ \\
\hline SPD_1355 & & Conserved hypothetical protein & 2.33 & $2.59 \mathrm{E}-04$ \\
\hline SPD_1357c & aliB & Oligopeptide $A B C$ transporter, oligopeptide-binding protein AliB & 2.53 & $1.95 \mathrm{E}-07$ \\
\hline SPD_1377 & & Conserved hypothetical protein & 2.42 & $4.77 \mathrm{E}-06$ \\
\hline SPD_1402 & & Non-heme iron-containing ferritin & 5.47 & $4.86 \mathrm{E}-10$ \\
\hline SPD_1439 & rpsO & Ribosomal protein S15 & 6.46 & $7.13 \mathrm{E}-30$ \\
\hline SPD_1535 & $s c r R$ & Sucrose operon repressor & 1.89 & $2.54 \mathrm{E}-04$ \\
\hline SPD_1577 & & Conserved hypothetical protein & 3.86 & $2.13 E-19$ \\
\hline SPD_1592 & & Acetyltransferase, GNAT family protein & 2.00 & $1.32 \mathrm{E}-03$ \\
\hline SPD_1594 & & Transcriptional regulator & 2.24 & $2.75 \mathrm{E}-06$ \\
\hline SPD_1595 & & Conserved hypothetical protein & 2.52 & $8.83 \mathrm{E}-07$ \\
\hline SPD_1603 & & Conserved hypothetical protein & 3.13 & $4.15 \mathrm{E}-06$ \\
\hline SPD_1604 & & Conserved hypothetical protein & 3.81 & $3.98 \mathrm{E}-15$ \\
\hline SPD_1614 & phoU2 & Phosphate transport system regulatory protein PhoU, putative & 1.88 & $3.49 \mathrm{E}-02$ \\
\hline SPD_1633 & galT-2 & Galactose-1-phosphate uridylyltransferase & 4.57 & $1.84 \mathrm{E}-15$ \\
\hline SPD_1634 & galk & Galactokinase & 3.73 & $1.59 \mathrm{E}-06$ \\
\hline SPD_1635 & galR & Galactose operon repressor & 2.46 & $3.17 \mathrm{E}-07$ \\
\hline SPD_1640 & pnuC & Nicotinamide mononucleotide transporter PnuC, putative & 9.39 & $6.74 \mathrm{E}-47$ \\
\hline SPD_1649c & piuB & Iron compound $\mathrm{ABC}$ transporter, permease protein & 2.00 & $3.22 \mathrm{E}-04$ \\
\hline SPD_1650' & piuc & Iron compound ABC transporter, permease protein & 1.93 & $2.58 \mathrm{E}-04$ \\
\hline SPD_1651 b,c & piuD & Iron compound ABC transporter, ATP-binding protein & 1.98 & $1.40 \mathrm{E}-04$ \\
\hline SPD_1665c & treR & Trehalose operon repressor & 2.18 & $2.53 \mathrm{E}-06$ \\
\hline SPD_1673c & $g t f A$ & Sucrose phosphorylase & 1.89 & $1.01 \mathrm{E}-03$ \\
\hline SPD_1676 & raff & Sugar $A B C$ transporter, permease protein & 2.89 & $2.85 \mathrm{E}-06$ \\
\hline SPD_1677c & rafE & Sugar $A B C$ transporter, sugar-binding protein & 2.76 & $1.19 \mathrm{E}-07$ \\
\hline SPD_1678 & aga & Alpha-galactosidase AgaN & 3.51 & $8.12 \mathrm{E}-13$ \\
\hline SPD_1679 & $m s m R$ & $m s m$ operon regulatory protein $\mathrm{MsmR}$ & 2.05 & $4.96 \mathrm{E}-05$ \\
\hline SPD_1680 & & Biotin-acetyl-CoA-carboxylase ligase & 2.19 & $2.04 \mathrm{E}-05$ \\
\hline SPD_1707 & & Conserved hypothetical protein & 13.5 & $1.50 \mathrm{E}-17$ \\
\hline SPD_1716 & & Conserved hypothetical protein & 1.94 & $4.20 \mathrm{E}-03$ \\
\hline SPD_1717 & & Membrane protein, putative & 1.81 & $1.07 \mathrm{E}-02$ \\
\hline SPD_1719 & & PAP2 family protein & 1.80 & $8.27 \mathrm{E}-03$ \\
\hline SPD_1720 & & Conserved hypothetical protein & 2.10 & $1.44 \mathrm{E}-03$ \\
\hline SPD_1830 & $\operatorname{bguA}$ & Glycosyl hydrolase, family protein 1 & 2.18 & $5.95 \mathrm{E}-06$ \\
\hline SPD_1831' & bguD & PTS system, IIC component & 2.27 & $1.41 \mathrm{E}-06$ \\
\hline SPD_1832 & $\operatorname{bgu} B$ & PTS system, IIB component & 2.08 & $2.76 \mathrm{E}-04$ \\
\hline SPD_1833' & bguC & PTS system, IIA component & 2.40 & $4.46 \mathrm{E}-07$ \\
\hline SPD_1865 & & Putative $\mathrm{Zn}$-dependent alcohol dehydrogenase & 2.12 & $7.51 \mathrm{E}-05$ \\
\hline SPD_1868 & $\operatorname{tgt}$ & tRNA-guanine transglycosylase & 2.05 & $1.34 \mathrm{E}-05$ \\
\hline SPD_1899 & & Glutamine amidotransferase, class 1 & 2.45 & $3.28 \mathrm{E}-04$ \\
\hline SPD_1910 ${ }^{h}$ & pstS1 & $\begin{array}{l}\text { Phosphate ABC transporter periplasmic-phosphate-binding } \\
\text { protein PstS1 }\end{array}$ & 3.87 & $5.51 E-08$ \\
\hline SPD_1911 ${ }^{h}$ & pstC1 & Phosphate transport system permease protein PstC1 & 2.87 & $2.97 E-03$ \\
\hline SPD_1912 ${ }^{h}$ & pstA1 & Phosphate transport system permease protein PstA1 & 2.77 & $1.37 \mathrm{E}-02$ \\
\hline SPD_1913 ${ }^{h}$ & pstB1 & Phosphate transport ATP-binding protein PstB1 & 2.64 & $2.23 E-02$ \\
\hline SPD_1914 ${ }^{h}$ & phoU1 & Phosphate transport system regulatory protein PhoU1 & 2.96 & $1.81 E-04$ \\
\hline SPD_1932 ${ }^{c}$ & malp & Maltodextrin phosphorylase & 2.47 & $4.54 \mathrm{E}-05$ \\
\hline SPD_1933c,h & malQ & 4-Alpha-glucanotransferase & 1.87 & $3.33 \mathrm{E}-02$ \\
\hline SPD_1962 ${ }^{c}$ & & Membrane protease family protein & 2.18 & $9.75 \mathrm{E}-06$ \\
\hline SPD_1976 & $\operatorname{arcB}$ & Ornithine carbamoyltransferase & 4.15 & $1.57 \mathrm{E}-21$ \\
\hline SPD_1977c & $\operatorname{arcc}$ & Carbamate kinase & 3.28 & $3.79 \mathrm{E}-15$ \\
\hline SPD_1978c & $\operatorname{arcD}$ & Arginine/ornithine antiporter $\mathrm{ArcD}$ & 3.48 & $1.43 \mathrm{E}-16$ \\
\hline SPD_1979 & & Putative Xaa-His dipeptidase & 3.55 & $8.53 \mathrm{E}-17$ \\
\hline SPD_1984 & $y b b k$ & Putative membrane protease subunit YbbK & 2.42 & $4.36 \mathrm{E}-04$ \\
\hline SPD_1989 & & Mannose-specific PTS IID component & 3.46 & $2.29 \mathrm{E}-04$ \\
\hline SPD_1996 & fucR & L-Fucose operon activator & 1.93 & $1.23 \mathrm{E}-04$ \\
\hline
\end{tabular}


TABLE 1 (Continued)

\begin{tabular}{|c|c|c|c|c|}
\hline spd gene tag & Gene & Known or predicted function & Fold change & $P_{\text {adj }}$ value \\
\hline SPD_2007 & & Macrolide-efflux protein & 2.63 & $4.89 \mathrm{E}-07$ \\
\hline SPD_2037 & cysk & Cysteine synthase & 1.85 & $2.71 E-02$ \\
\hline SPD_2042 & $r p s B$ & Ribosomal protein S2 & 15.6 & $5.46 \mathrm{E}-73$ \\
\hline \multicolumn{5}{|c|}{$\begin{array}{c}\text { Decreased relative } \\
\text { expression }\end{array}$} \\
\hline SPD_0383c & $f a b D$ & Malonyl CoA-acyl carrier protein transacylase & 0.54 & $2.06 \mathrm{E}-03$ \\
\hline SPD_0390c & $\operatorname{acc} A$ & Acetyl-CoA carboxylase, carboxyl transferase, alpha subunit & 0.55 & $6.08 \mathrm{E}-03$ \\
\hline SPD_0447 & & Transcriptional regulator, MerR family protein & 0.49 & $1.79 \mathrm{E}-03$ \\
\hline SPD_0448 & & Glutamine synthetase, type I & 0.44 & $2.05 \mathrm{E}-03$ \\
\hline SPD_0449 & & Conserved hypothetical protein & 0.31 & $8.77 \mathrm{E}-05$ \\
\hline SPD_0451 & & Type I restriction-modification system, S subunit, putative & 0.45 & $9.10 \mathrm{E}-04$ \\
\hline SPD_0675 & & Conserved hypothetical protein & 0.55 & $5.79 \mathrm{E}-03$ \\
\hline SPD_1410 & & tRNA-Leu & 0.49 & $4.64 \mathrm{E}-02$ \\
\hline SPD_1683 & & tRNA-Ile & 0.52 & $4.39 \mathrm{E}-03$ \\
\hline SPD_1691 & & tRNA-Arg & 0.49 & $9.77 \mathrm{E}-04$ \\
\hline SPD_1789 & & Cell wall surface anchor family protein & 0.45 & $1.99 \mathrm{E}-05$ \\
\hline SPD_1801 & & $\mathrm{ABC}$ transporter, ATP-binding protein & 0.41 & $4.40 E-04$ \\
\hline SPD_1802 & & Conserved hypothetical protein & 0.42 & $8.26 \mathrm{E}-06$ \\
\hline SPD_1803 & & Conserved hypothetical protein & 0.45 & $4.57 \mathrm{E}-03$ \\
\hline SPD_1879 & & tRNA-Leu & 0.47 & $4.14 \mathrm{E}-03$ \\
\hline SPD_1881 & & tRNA-His & 0.55 & $2.74 \mathrm{E}-02$ \\
\hline SPD_2011c & & Glycerol uptake facilitator protein & 0.41 & $1.25 \mathrm{E}-02$ \\
\hline SPD_2012 & & Alpha-glycerophosphate oxidase & 0.42 & $1.30 \mathrm{E}-03$ \\
\hline
\end{tabular}

aRNA extraction and mRNA-seq analyses were performed as described in Materials and Methods. RNA was prepared from cultures of isogenic strains IU3116 (wild-type

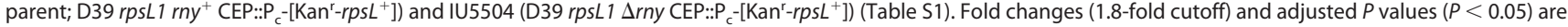
based on three independent biological replicates. Boldface indicates genes mentioned in the text.

${ }^{b}$ Member of the CbpRS two-component system regulon (82).

cMember of the SaeRS two-component system regulon (83).

${ }^{d}$ Member of the WalRK two-component system regulon (55).

eMember of the TCS07/YesMN two-component system regulon (84).

${ }^{f}$ Member of the LiaFSR two-component system regulon (58).

9 Member of the CiaRH two-component system regulon (85).

${ }^{h}$ Member of the PnpRS two-component system regulon (67).

RNase $\mathbf{Y}$ and PNPase mediate the sRNA transcriptome of $\mathbf{S}$. pneumoniae. Previous studies demonstrate that RNase $\mathrm{Y}$ directly and indirectly impacts sRNA levels in several important Gram-positive pathogens $(25,36,37)$, whereas PNPase promotes the stability of some sRNAs and degrade others in $\operatorname{E}$. coli $(38,39)$. A recent Grad-seq study indicates that S. pneumoniae PNPase binds to several sRNAs, including $\mathrm{CcnA}, \mathrm{CcnB}, \mathrm{CcnC}$, CcnD, and Spd_sr34 (23). To further understand how RNases modulate the stability and function of sRNAs expressed by S. pneumoniae D39, we sought to identify the sRNAs targeted by RNase $\mathrm{Y}$ and PNPase using sRNA sequencing (sRNA-seq) (see Materials and Methods). At least 112 distinct sRNAs have been identified in S. pneumoniae D39 (40-45).

sRNA-seq analysis revealed that 11 sRNAs ( $\sim 10 \%$ of total sRNAs) showed a $>1.8$ fold change in relative amount between the $\Delta r n y$ mutant and WT strain (Table 3; Fig. 3A). Seven sRNAs were upregulated in the $\Delta$ rny mutant compared to the WT strain, whereas only 4 were downregulated. The putative regulatory RNAs impacted by $\Delta r n y$ fall into all five categories of SRNAs based on their location relative to previously annotated genes in D39 (Fig. 3B). Three of the sRNAs differentially expressed in the $\Delta r n y$ mutant contain regulatory elements; Spd-sr12 and Spd-sr32 contain T-box riboswitches, and Spd-sr48 has an L20 leader sequence that regulates the expression of 
A

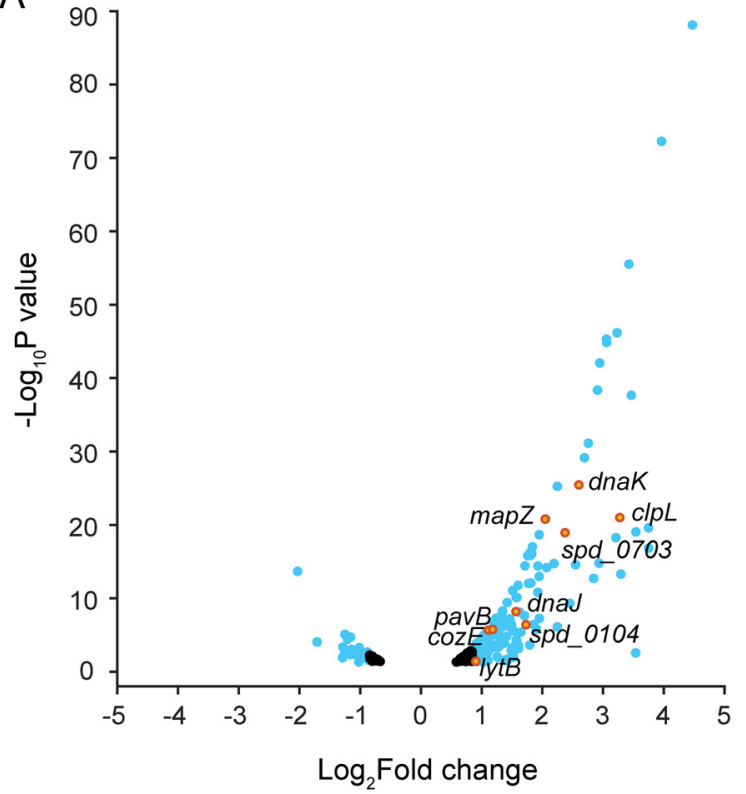

C

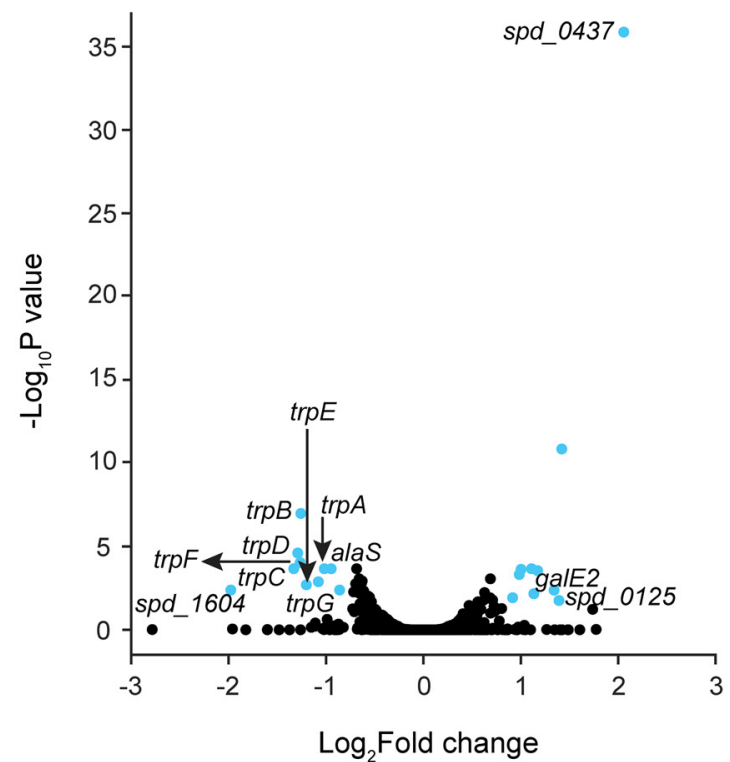

B
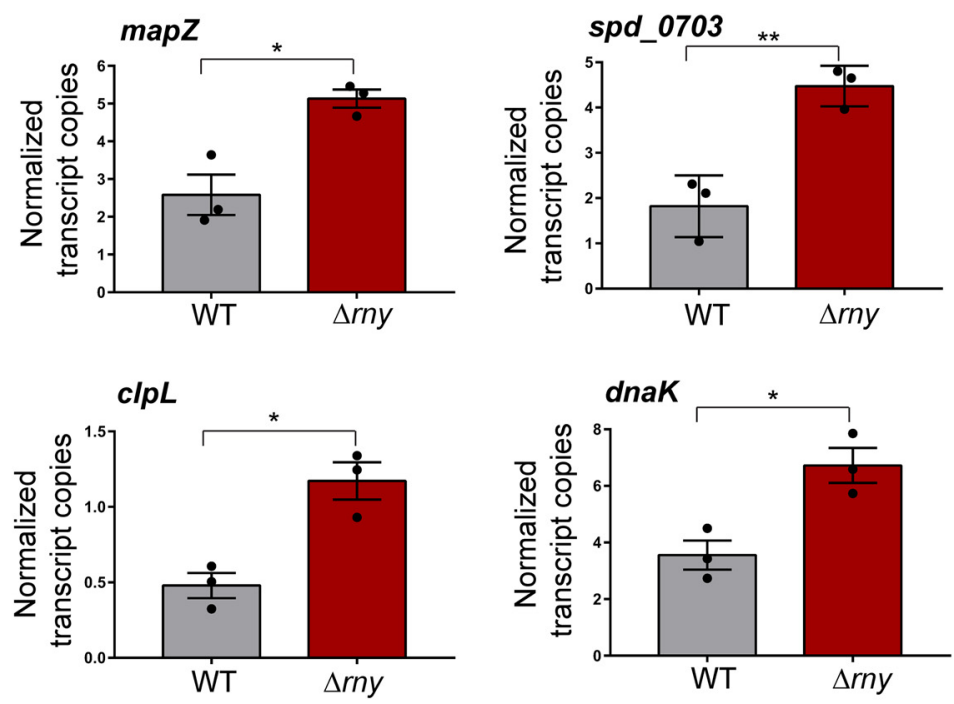

D
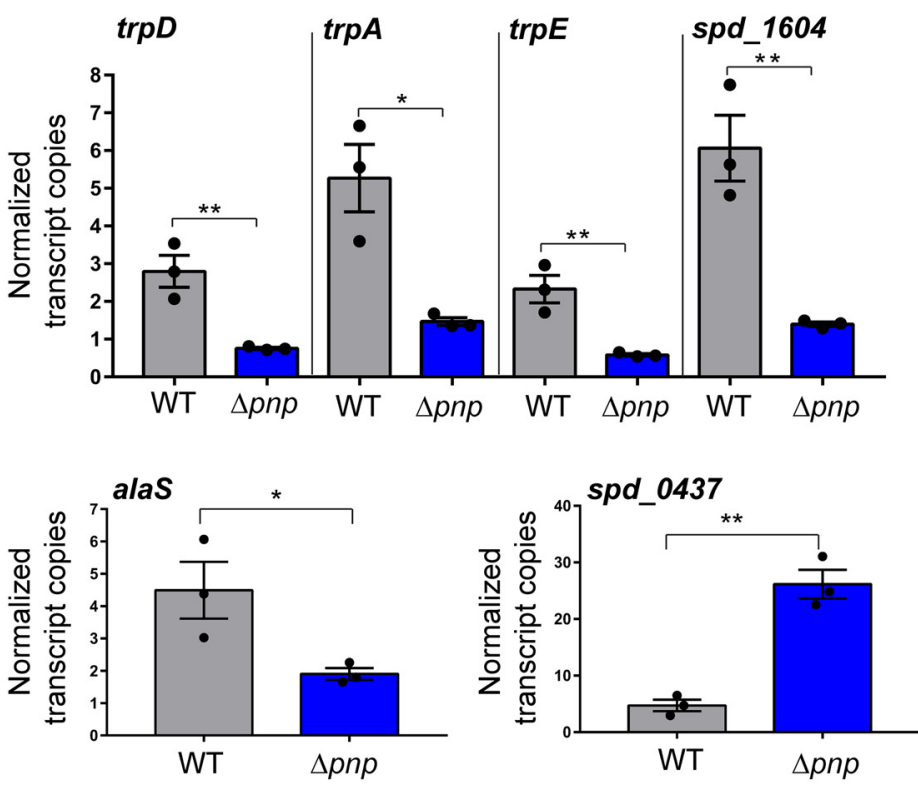

FIG 2 Impact of RNase $Y$ and PNPase on mRNA transcriptome of S. pneumoniae D39. (A and C) Volcano plots showing genome-wide changes in mRNA transcript levels in a $\Delta r n y$ mutant (A) and a $\Delta p n p$ mutant (C) relative to the D39 parent strain. RNA was extracted from exponentially growing cultures of the WT D39 parent (IU3116) and isogenic $\Delta r n y$ (IU5504) and $\Delta p n p$ (IU5498) mutants in triplicate and analyzed by mRNA-seq as described in Materials and Methods. Orange and cyan dots represent genes with relative transcript changes of $>1.8$-fold as the cutoff (log fold change $=0.85$ ), with an adjusted $P$ value cutoff of $<0.05$. Relative transcript level changes of genes below the cutoff values are considered insignificant and are in black. The $x$ axis represents gene fold changes, and the $y$ axis represents corresponding $P$ values plotted on a logarithmic scale. mRNAs that were significantly upregulated or downregulated in the $\Delta$ rny mutant or $\Delta p n p$ mutant compared to the parent are listed in Tables 1 and 2 , respectively. (B and D) ddPCR analysis was used to determine copy numbers of indicated transcripts in a wild-type D39 parent (WT; IU1781) and isogenic mutants ( $\Delta r n y$, NRD10092; $\Delta p n p$, IU4883). Transcript numbers were normalized to the $16 \mathrm{~S}$ transcript number, which served as the internal control. Bars and error bars represent the means and standard errors of the means (SEM) from at least three independent experiments. ${ }^{*}, P<0.05 ;{ }^{* *}, P<0.01$.

downstream ribosomal genes. Interestingly, among the significantly upregulated sRNAs in the $\Delta$ rny mutant are 2 Ccn sRNAs (CcnA and CcnE) (Table 3; Fig. 3A), which are among the five homologous, highly conserved intergenic pneumococcal sRNAs under positive transcriptional control of the CiaR response regulator and function to inhibit competence development via base-pairing with the precursor of the competence stimulatory peptide-encoding mRNA comC $(86,87)$. Seven of 11 sRNAs that were 
TABLE 2 Genes showing changes in relative mRNA transcript amounts in a $\Delta p n p$ mutant compared to the $p n p^{+}$parent strain during exponential growth in $\mathrm{BHI}$ broth $^{a}$

\begin{tabular}{|c|c|c|c|c|}
\hline spd tag no. & Gene & Known or predicted function & Fold change & $P_{\text {adj }}$ value \\
\hline \multicolumn{5}{|c|}{ Increased relative expression } \\
\hline SPD_0125 & & Hypothetical protein & 2.62 & $1.72 \mathrm{E}-02$ \\
\hline SPD_0437 ${ }^{b}$ & ribU & Substrate-specific component RibU of riboflavin ECF transporter & 4.16 & $1.33 \mathrm{E}-36$ \\
\hline SPD_0975 & $\operatorname{radC}$ & DNA repair protein RadC & 2.00 & $4.75 \mathrm{E}-04$ \\
\hline SPD_1579 & & Hypothetical protein & 2.53 & $4.13 E-03$ \\
\hline SPD_1586 & & Multiple sugar metabolism operon regulatory protein & 2.68 & $1.39 \mathrm{E}-11$ \\
\hline SPD_1707 & & Hypothetical protein & 2.25 & $2.79 \mathrm{E}-04$ \\
\hline SPD_1792 & & Hypothetical protein & 2.16 & $2.13 \mathrm{E}-04$ \\
\hline \multicolumn{5}{|c|}{ Decreased relative expression } \\
\hline SPD_1216 & alas & Alanyl-tRNA synthetase & 0.52 & $2.13 \mathrm{E}-04$ \\
\hline SPD_1596 & $\operatorname{trpA}$ & Tryptophan synthase alpha chain & 0.49 & $2.13 \mathrm{E}-04$ \\
\hline SPD_1601 & $\operatorname{trpG}$ & Bifuncational anthranilate synthase & 0.44 & $1.97 \mathrm{E}-03$ \\
\hline SPD_1602 $2^{b, d}$ & $\operatorname{trp} E$ & Anthranilate synthase, amidase component & 0.47 & $1.29 E-03$ \\
\hline SPD_1604 & & Hypothetical protein & 0.25 & $4.06 \mathrm{E}-03$ \\
\hline SPD_2012 & $g \mid p O$ & Alpha-glycerophosphate oxidase & 0.55 & $4.06 \mathrm{E}-03$ \\
\hline
\end{tabular}

aRNA extraction and mRNA-seq analyses were performed as described in Materials and Methods. RNA was prepared from cultures of isogenic strains IU3116 (wild-type

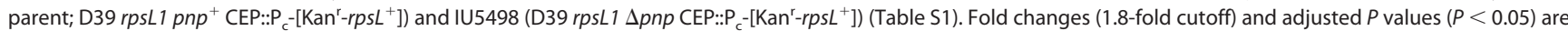
based on three independent biological replicates.

${ }^{b}$ Role in virulence according to Tn-seq studies in TIGR4 (36).

'Likely essential gene according to Tn-seq studies in TIGR4 (36).

${ }^{d}$ Member of the tryptophan (trp) biosynthesis operon.

differentially expressed in the $\Delta r n y$ mutant relative to the WT strain were experimentally validated using Northern blotting. We found that four sRNAs (CcnE, CcnA, Spdsr12, and Spd-sr32) are significantly upregulated, while for the sRNAs Spd-sr100 and Spd-sr116, the annotated full-length transcripts could not be detected in the $\Delta r n y$ mutant (Fig. 4; Fig. S3 and S5). However, we did observe that a higher-molecular-weight

TABLE 3 Relative sRNA transcript level changes in strain a $\Delta$ rny mutant compared to the rny ${ }^{+}$parent strain during exponential growth in $\mathrm{BHI}_{\text {broth }^{a}}$

\begin{tabular}{llll}
\hline sRNA ID & Flanking genes & Fold change & $P_{\text {adj }}$ \\
\hline Increased relative expression & & & $2.87 \mathrm{E}-09$ \\
CcnE & spd_0221, spd_0222 & 2.05 & $3.56 \mathrm{E}-03$ \\
CcnA & spd_0240, ruvB & 1.86 & $4.24 \mathrm{E}-18$ \\
SPD_SR32 ${ }^{b}$ & spd_0490, spd_0491 & 3.77 & $9.22 \mathrm{E}-41$ \\
SPD_SR33 & spd_0500, licT & 14.8 & $3.46 \mathrm{E}-02$ \\
SPD_SR12 ${ }^{b}$ & ppC,spd_0954 & 15.2 & $7.75 \mathrm{E}-36$ \\
SPD_SR107 & malP,spd_1931 & 3.37 & $3.73 \mathrm{E}-48$ \\
SPD_SR116 & spd_2043, rpsB & 3.86 & \\
& & & $2.31 \mathrm{E}-10$ \\
Decreased relative expression & & & $2.36 \mathrm{E}-08$ \\
SPD_SR48 ${ }^{b}$ & spd_0846, infC & -2.46 & $6.02 \mathrm{E}-03$ \\
SPD_SR84 & spd_1578, spd_1577 & -2.05 & 0.0018 \\
SPD_SR100 & pbp2A,secE & -1.92 & -2.18 \\
SPD_SR108 & spd_1939, malR & & \\
\hline
\end{tabular}

aRNA extraction and sRNA-seq analyses were performed as described in Materials and Methods. RNA was prepared from cultures of the encapsulated parent strain IU1781 (wild-type parent; D39 rpsL1 rny ${ }^{+}$) and its derived mutant NRD10092 (D39 rpsL1 $\Delta$ rny) (Table S1). Fold changes (1.8-fold cutoff) and $P$ values $\left(P_{\text {adj }}<0.05\right)$ are based on three independent biological replicates. sRNAs validated in this study are in bold (Fig. 4; Fig. S3 and S5).

${ }^{b 5}$ ' regulatory element present.

'Spd-sr108 levels were comparable between the wild type and a $\Delta$ rny mutant on Northern blots (Fig. S5). 
A

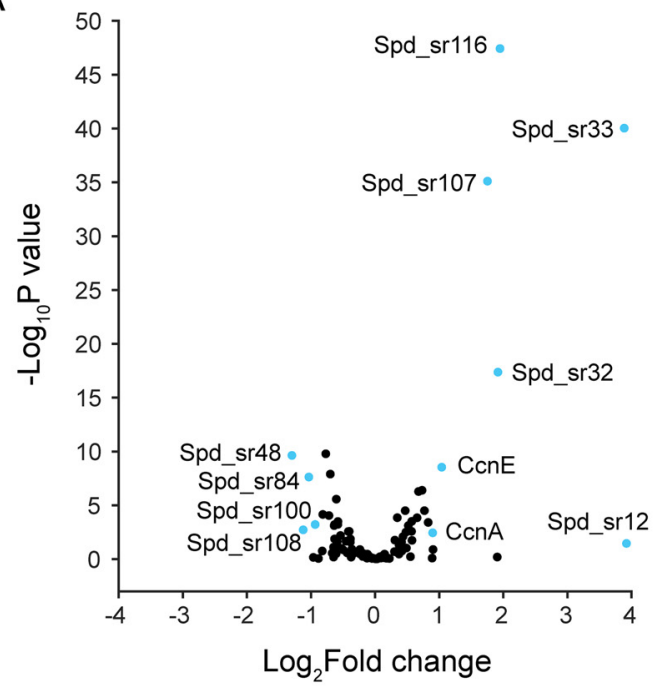

B

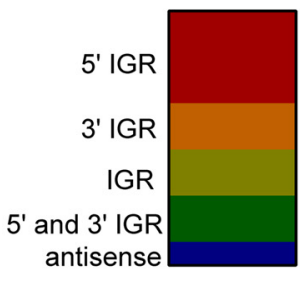

C

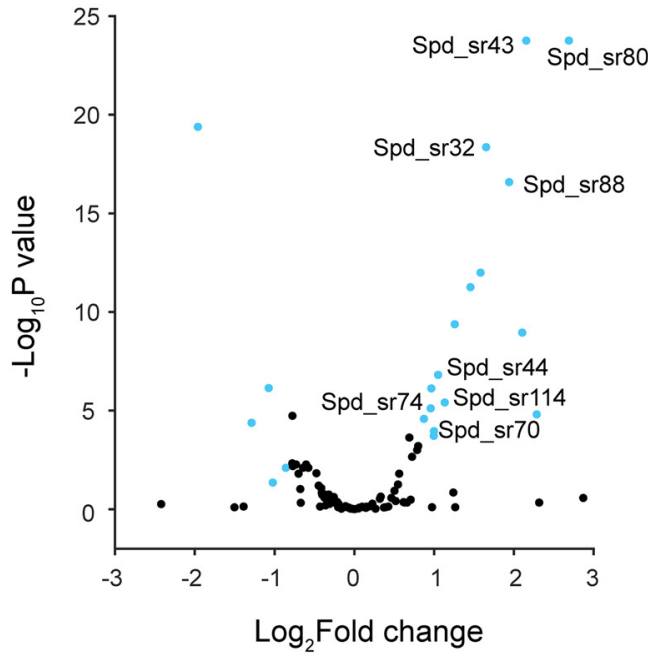

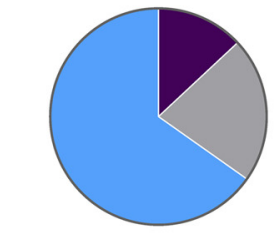

- TPP-riboswitch RNAs (3)

$\square$ T-box-riboswitch RNAs (5)

$\square$ sRNAs (15)

FIG 3 Impact of RNase $Y$ and PNPase on sRNA transcriptome of S. pneumoniae D39. (A and C) Volcano plot showing genome-wide changes in sRNA transcript levels in a $\Delta r n y$ mutant (A) or $\Delta p n p$ mutant (C) relative to the D39 parent strain. RNA was extracted from exponentially growing cultures of the WT D39 parent (IU1781) and isogenic $\Delta r n y$ (NRD10092) and $\Delta p n p$ (IU4883) mutants in triplicate and analyzed by sRNA-seq analysis as described in Materials and Methods. Cyan dots represent genes with relative transcript changes of $>1.8$-fold as the cutoff ( $\log _{2}$ fold change $=0.85$ ), with an adjusted $P$ value cutoff of $<0.05$. Relative transcript level changes of genes below the cutoff values are considered insignificant and are in black. The $x$ axis represents gene-fold changes, and the $y$ axis represents corresponding $P$ values plotted on a logarithmic scale. sRNAs that were significantly upregulated or downregulated in the $\Delta r n y$ mutant or $\Delta p n p$ mutant compared to the parent are listed in Tables 3 and 4, respectively. (B and D) Distribution of sRNAs that were differentially regulated in a $\Delta r n y$ mutant (B) or a $\Delta p n p$ (D) mutant compared to the parent in different genomic contexts as described previously (40). Pie chart graphs indicate the percent distribution of the sRNAs based on the presence or absence of $5^{\prime}$ cis-regulatory elements in their sequence. IGR, intergenic region.

band corresponding to Spd-sr116 was increased in abundance only in a $\Delta$ rny mutant (Fig. S3). Spd-sr108 was the only sRNA for which we observed a significant difference in abundance between the $\Delta r n y$ mutant and WT strain by RNA-seq but not by Northern blotting analysis (Table 3; Fig. S3 and S5). In addition to these sRNAs, we probed for 12 additional sRNAs that were not significantly differentially expressed in the $\Delta r n y$ mutant relative to the WT strain in the RNA-seq analysis. Northern blots revealed that eight of these sRNAs (Spd-sr43, Spd-sr44, Spd-sr73, Spd-sr74, Spd-sr80, Spd-sr83, Spd-sr88, and Spd-sr114) were upregulated in the $\Delta r n y$ mutant relative to the wild-type strain, whereas 4 others (Spd-sr70, Spd-sr54, Spd-sr82, and Spd-sr96) were unaffected by $\Delta r n y$ (Fig. 4; Fig. S3 and S5). Together, these data confirm that the cellular amounts of a relatively small number of sRNAs are changed in the $\Delta r n y$ mutant.

In contrast to the $\Delta r n y$ mutant, $21 \%$ of the pneumococcal sRNA transcriptome was significantly altered in the $\Delta p n p$ mutant. Twenty-three sRNAs exhibited $>1.8$-fold differences in relative expression in the $\Delta p n p$ mutant (Table 4; Fig. 3C), where 17 and 6 sRNAs were significantly up- and downregulated, respectively. Notably, approximately half of the sRNAs upregulated in a $\Delta p n p$ mutant relative to the WT strain are riboswitch RNAs. Spd-sr32, Spd-sr70, Spd-sr74, Spd-sr80, and Spd-sr88 are characterized by the 
A

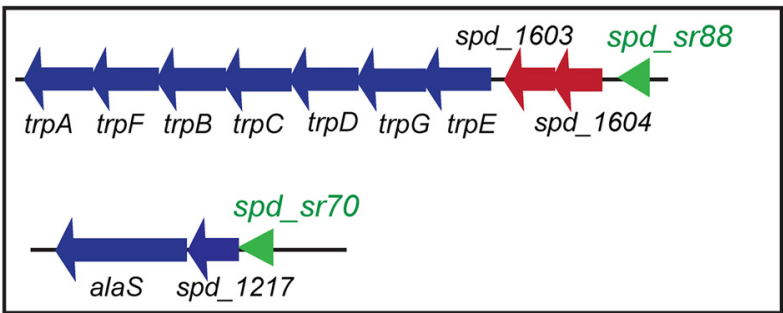

C

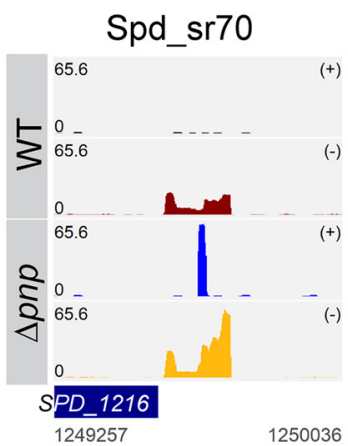

$E$

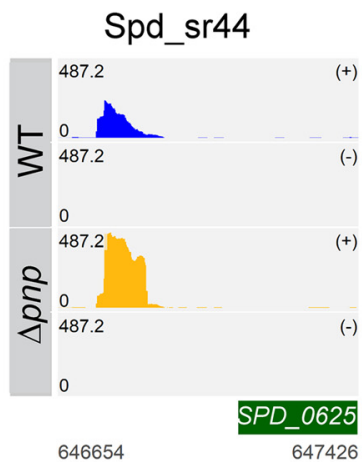

G

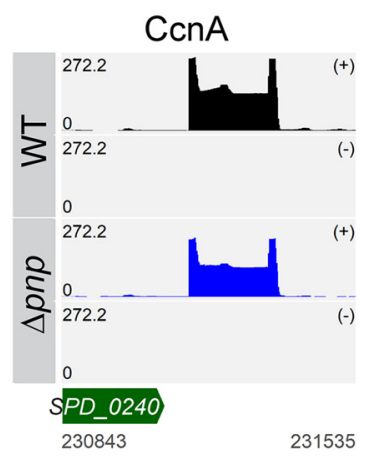

B

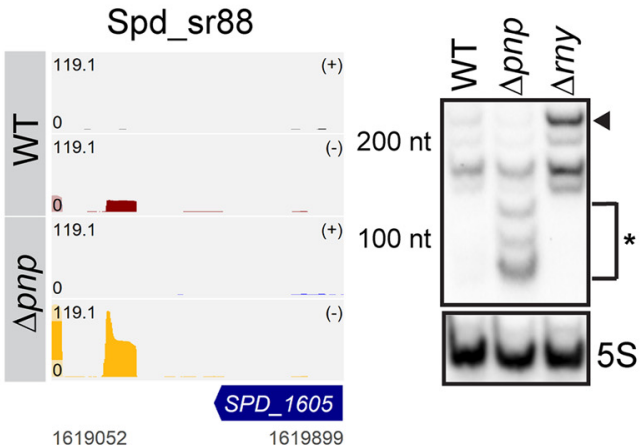

D

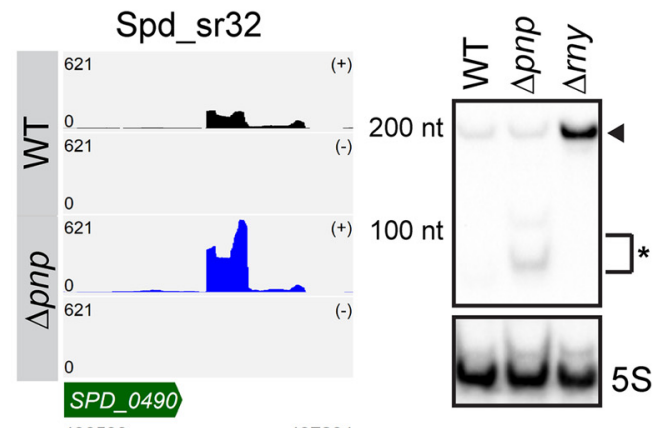

F

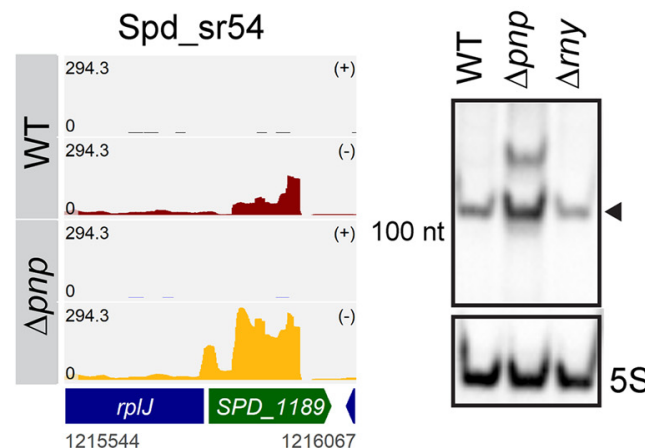

$\mathrm{H}$

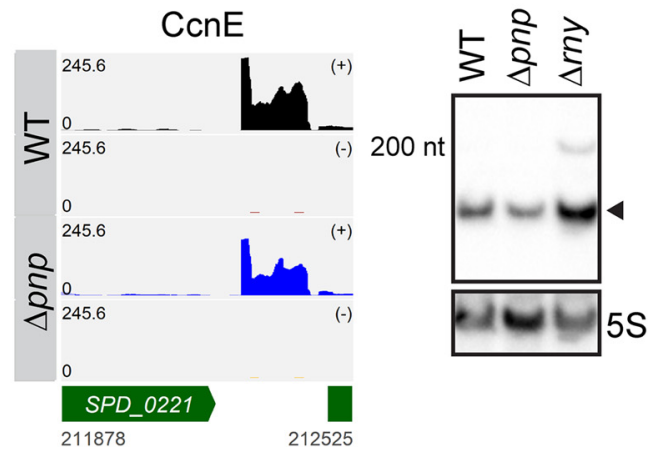

FIG 4 PNPase plays an important role in the decay and processing of riboswitch RNAs in S. pneumoniae D39. (A) Genetic context of two Tbox riboswitches, Spd-sr88 and Spd-sr70, in S. pneumoniae D39. (B to H) Read coverage maps of a subset of sRNAs and their flanking regions that were differentially regulated in a $\Delta p n p$ mutant (IU4883) compared to the WT parent (IU1781) in sRNA-seq. Coverage represents depth per million reads of paired-end sRNA fragments and was averaged between normalized replicates (see Materials and Methods). In each coverage graph, open reading frames (ORFs) encoded on the plus or minus strand are in green or blue, respectively. Northern blots detecting the sRNAs are presented alongside the read coverage maps. Black triangles and asterisks indicate the full-length sRNA transcripts and sRNA decay products, respectively. Corresponding coverage maps for the sRNAs presented in panels B to $\mathrm{H}$ in a $\Delta r n y$ mutant (NRD10092) compared to the WT parent (IU1781) are presented in Fig. S4. Quantification of signal intensity for each full-length sRNA normalized to 5 S rRNA amount is displayed in Fig. S5, and the probes used are listed in Table S3. 
TABLE 4 Relative sRNA transcript level changes in a $\Delta p n p$ mutant compared to the $p n p^{+}$ parent strain during exponential growth in $\mathrm{BHI}$ broth $^{a}$

\begin{tabular}{|c|c|c|c|}
\hline sRNA ID & Flanking genes & Fold change & $P_{\text {adj }}$ \\
\hline \multicolumn{4}{|c|}{ Increased relative expression } \\
\hline SPD_SR32 ${ }^{b}$ & spd_0490,spd_0491 & 3.14 & $4.39 \mathrm{E}-19$ \\
\hline SPD_SR33 & spd_0500, lict & 4.88 & $1.55 \mathrm{E}-05$ \\
\hline SPD_SR43 ${ }^{c}$ & IctO, spd_0622 & 4.45 & $1.74 \mathrm{E}-24$ \\
\hline SPD_SR44c & thiE1, spd_0625 & 2.07 & $1.54 \mathrm{E}-07$ \\
\hline SPD_SR57 & spd_0988, spd_0987 & 1.83 & $2.62 \mathrm{E}-05$ \\
\hline SPD_SR54 & spd_1190, rplJ & 1.95 & $7.51 \mathrm{E}-07$ \\
\hline SPD_SR70 ${ }^{b}$ & spd_1216, spd_1217 & 2.00 & 0.00011 \\
\hline SPD_SR73 & spd_1289, spd_1288 & 2.39 & $4.19 \mathrm{E}-10$ \\
\hline SPD_SR74 ${ }^{b}$ & spd_1308, spd_1307 & 1.94 & $7.70 \mathrm{E}-06$ \\
\hline SPD_SR77 & $a s n \bar{S}, r p s F$ & 2.00 & 0.00019 \\
\hline SPD_SR80 ${ }^{b}$ & spd_1441,spd_1442 & 6.45 & $1.74 \mathrm{E}-24$ \\
\hline SPD_SR81 & spd_1448, spd_1447 & 4.30 & $1.11 \mathrm{E}-09$ \\
\hline SPD_SR82 & spd_1455, spd_1454 & 2.74 & $5.50 E-12$ \\
\hline SPD_SR88 ${ }^{b}$ & spd_1605, spd_1604 & 3.84 & $2.60 \mathrm{E}-17$ \\
\hline SPD_SR100 & $p b p 2 A, \sec E$ & 17.9 & $5.51 \mathrm{E}-75$ \\
\hline SPD_SR114 ${ }^{c}$ & cbpD,spd_2027 & 2.19 & $3.88 \mathrm{E}-06$ \\
\hline SPD_SR116 & spd_2043, rpsB & 2.99 & $1.01 \mathrm{E}-12$ \\
\hline \multicolumn{4}{|c|}{ Decreased relative expression } \\
\hline $\operatorname{CcnA}^{d}$ & spd_0240, ruvB & -2.03 & $4.46 \mathrm{E}-02$ \\
\hline SPD_SR36 & metF, pnp & -15.9 & $1.36 \mathrm{E}-60$ \\
\hline SPD_SR61 & spd_1080,spd_1079 & -2.11 & $7.19 E-07$ \\
\hline SPD_SR83 & $\operatorname{rec} \bar{G}$, spd_1506 & -3.90 & $4.12 \mathrm{E}-20$ \\
\hline SPD_SR95 & $\operatorname{dinF}$, lytA & -2.44 & $4.17 \mathrm{E}-05$ \\
\hline SPD_SR101 & spd_1834, spd_1833 & -1.81 & $7.93 \mathrm{E}-03$ \\
\hline \multicolumn{4}{|c|}{$\begin{array}{l}\text { aRNA extraction and sRNA-seq analyses were performed as described in Materials and Methods. RNA was } \\
\text { prepared from cultures of the encapsulated parent strain IU1781 (wild-type parent; D } 39 \text { rpsL1 pnp } p^{+} \text {) and its } \\
\text { derived mutant IU4883 (D39 rpsL1 } \triangle p n p \text { ) (Table S1). Fold changes (1.8-fold cutoff) and } P \text { values }\left(P_{\text {adj }}<0.05 \text { ) are }\right. \\
\text { based on three independent biological replicates. sRNAs validated in this study are in bold (Fig. 4; Fig. S3 and S5). } \\
{ }^{6} 5^{\prime} \text { regulatory element and T-box element present. } \\
{ }^{5}{ }^{\prime} \text { regulatory element and TPP riboswitch element present. }\end{array}$} \\
\hline
\end{tabular}

presence of a T-box riboswitch, while Spd-sr43, Spd-sr44, and Spd-sr114 contain a thiamine pyrophosphate (TPP) riboswitch element (Table 4; Fig. 3C and D). The riboswitch RNAs Spd-sr44 and Spd-sr88 are particularly interesting, because Tn-seq screens with the serotype 4 strain (TIGR4) of S. pneumoniae indicated that the loss of spd-sr44 or spd-sr88 results in reduced pneumococcal fitness in murine blood and lung infection, respectively (46). 5'-intergenic and $3^{\prime}$-intergenic sRNAs are in the overrepresented category of sRNAs that showed differential regulation in $\Delta p n p$ compared to the WT strain (Fig. 3D). Finally, we validated the expression of a total of 14 of 23 sRNAs that were significantly differentially expressed in the $\Delta p n p$ mutant relative to the WT strain (Fig. 4; Fig. S3 and S5). Taken together, these data suggest that both RNase Y and PNPase play important roles in regulating the relative amounts of different sets of pneumococcal regulatory RNAs.

PNPase and RNase Y play important roles in riboswitch RNA decay and processing. T-box-containing riboswitch RNAs that are upregulated in the $\Delta p n p$ mutant include Spd-sr88 and Spd-sr70, which are located within the $5^{\prime}$ untranslated regions (UTRs) of the trp operon (encoding enzymes involved in tryptophan biosynthesis) and alaS (encoding alanyl-tRNA synthetase) operon, respectively (Table 4; Fig. 4A). Northern blotting confirmed increases in spd-sr88 and spd-sr70 in the $\Delta p n p$ mutant compared to the WT strain determined by RNA-seq analysis (Table 4) and showed accumulations of decay products of these sRNAs (Fig. 4B and C). Concurrently, relative transcript amounts of both alaS and the entire trp operon, including the upstream gene spd_1604, are decreased by $\sim 2$-fold and $\sim 2$ - to 4-fold, respectively, in the $\Delta p n p$ mutant in mRNA-seq analysis (Table 2; Fig. $3 C$ and D). Based on these observations, we 
further tested the expression profiles of six other TPP or T-box riboswitch RNAs that also showed increased relative expression in the $\Delta p n p$ mutant (Table 4). We observed a similar pattern of accumulation of decay intermediates for Spd-sr32, Spd-sr43, Spdsr44, Spd-sr74, Spd-sr80, and Spd-sr114 in the $\Delta$ pnp mutant, but not in the WT or $\Delta r n y$ strain (Fig. 4D and E; Fig. S3). In addition, we noticed that the full-length transcripts for all six of these riboswitch RNAs were more abundant in a $\Delta r n y$ mutant than that in a WT strain (Fig. 4B and D; Fig. S3 and S4). While Spd-sr32 was identified by sRNA-seq analysis to be significantly upregulated by $\sim 4$-fold in the $\Delta$ rny mutant compared to WT (Table 3), the increased relative transcript steady-state levels of the other riboswitch RNAs (Spd-sr43, Spd-Sr44, Spd-sr74, Spd-sr88, and Spd-sr114) in a $\Delta r n y$ mutant were not detected by this transcriptomics-based approach but were detected independently by Northern blot analysis (Fig. S3). Taking these results together, we conclude that both RNase $\mathrm{Y}$ and PNPase jointly function in the processing and decay of riboswitch regulatory RNAs.

RNase $\mathrm{Y}$ regulates $\mathrm{Ccn}$ sRNA stability and function. After validating by Northern blotting, the $\sim 3$-fold increases in relative steady-state levels of $\operatorname{CnA}$ and $C \mathrm{cnE}$ in the $\Delta$ rny mutant (Fig. 4G and H; Fig. 5A, B, D, and E; Fig. S6) in accordance with our sRNAseq data (Table 3 ), we sought to further define the mechanism by which RNase $Y$ regulates of the abundance of the Ccn sRNAs in S. pneumoniae D39. Therefore, we measured the stability of $\mathrm{Ccn} A$ and $\mathrm{CcnE}$ in exponentially growing cultures of a $\Delta$ rny mutant or a WT strain after blocking transcription initiation by adding rifampin (Fig. 5C and F). The relative half-life $\left(t_{1 / 2}\right)$ of CcnA increased by approximately 3-fold in the $\Delta$ rny mutant compared to the WT $\left(t_{1 / 2}=52.2 \mathrm{~min}\right.$ versus $17.6 \mathrm{~min}$ [Fig. $5 \mathrm{C}$ ]), while that of CcnE increased by $\sim 2$-fold ( $t_{1 / 2}=28.4 \mathrm{~min}$ versus $15.8 \mathrm{~min}$ [Fig. 5F]) (Table S4). These findings prompted us to test the impact of RNase $Y$ on the stability and the corresponding steady-state levels of the remaining three $\mathrm{Ccn}$ sRNAs. The relative transcript levels for $\mathrm{CcnB}, \mathrm{CcnC}$, and $\mathrm{CcnD}$, were similarly upregulated by $\sim 2$-fold in the $\Delta r n y$ mutant compared to WT (Fig. 5G). Consistent with these increased amounts, CcnB and CcnC were significantly stabilized in the $\Delta$ rny mutant (Fig. $5 \mathrm{H}$ and I; Table S4). We were unable to accurately determine the relative stability of $\mathrm{CcnD}$, because it was extremely unstable in the WT strain following rifampin addition (data not shown).

Finally, we investigated the role of RNase $\mathrm{Y}$ in Ccn-mediated comC target regulation. To this end, we constructed a translational fusion in which the $5^{\prime}$ untranslated region and the first 12 codons of com $C$ are fused in-frame with the truncated $E$. coli $\beta$-galactosidase gene lacZ. The comC'-'lacZ translational fusion, driven from the constitutive vegetative promoter vegT (derived from the vegll promoter of Bacillus subtilis [Tables S1 and S2]), was integrated in the chromosomal bgaA locus in strain D39 (thereby knocking out pneumococcal $\beta$-galactosidase). Consistent with previous reports, deletion of all 5 Ccn sRNAs ( $\triangle c c n A-E$ ) relieved ComC translational repression and led to increased relative expression of $\beta$-galactosidase specific activity $(\sim 3.5$-fold) from comC-'lac $Z$ (Fig. 5J). Conversely, $\Delta$ rny led to decreased ( $\sim 3.8$-fold) relative $\beta$-galactosidase specific activity from the comC-'lacZ fusion (Fig. 5J), consistent with increased stabilization of Ccn sRNAs (Fig. 4) and increased translational repression of ComC. To further test this idea, we attempted to measure comC-'lacZ expression in a $\Delta r n y \Delta c c n A-E$ mutant. Unexpectedly, the $\Delta r n y \Delta c c n A-E$ mutant exhibited a synthetic phenotype with severely impaired growth and low growth yield compared to the WT (data not shown). In contrast, a $\triangle$ rny $\triangle c c n A C D E$ mutant did not exhibit a strong synthetic phenotype (data not shown). Relative expression of $c o m C$-'lacZ is less elevated in the $\triangle c c n A C D E$ than the $\triangle c c n A-E$ mutant and is reduced further in the $\triangle r n y=\triangle c c n A C D E$ mutant to near the WT level (Fig. 5J), consistent with stabilization of remaining $\mathrm{CcnB}$ in the $\Delta r n y$ background. However, the transformation frequency (TF) of a $\Delta$ rny mutant was comparable to that of a WT strain $\left(\mathrm{TF}_{\Delta r n y}=0.38 \%\right.$ versus $\mathrm{TF}_{\mathrm{WT}}=$ $0.32 \%)$, using a spontaneous competence assay (Fig. S2B). Together, these results indicate that RNase Y-mediated regulation of Ccn sRNA stability has a consequential impact on Ccn-mediated target regulation in S. pneumoniae D39. 
A

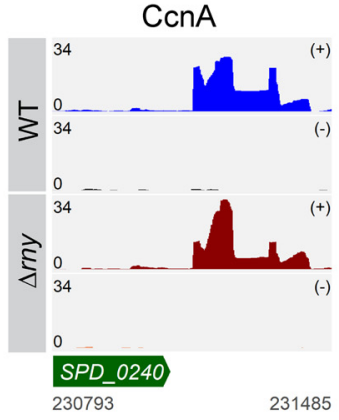

D

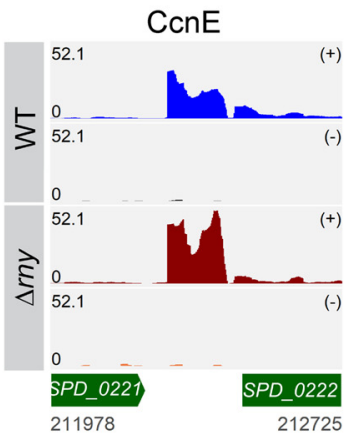

B

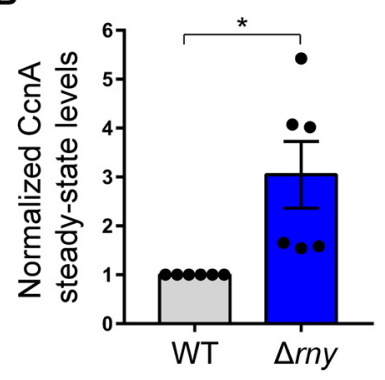

E

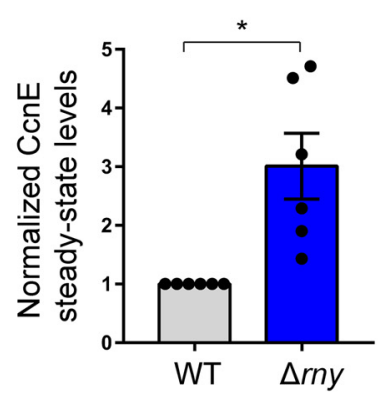

C

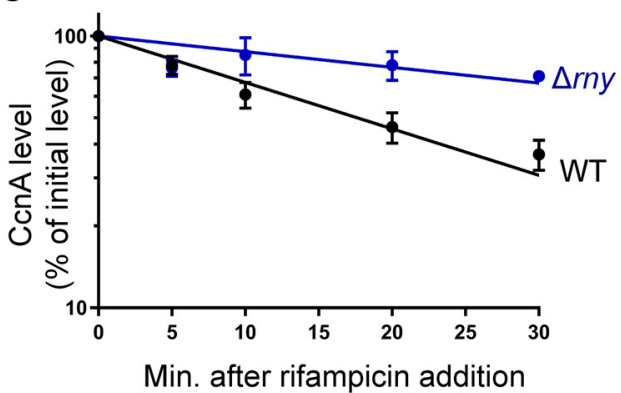

F

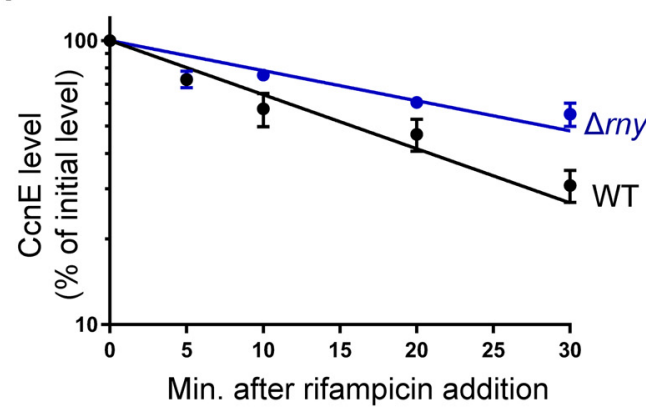

G

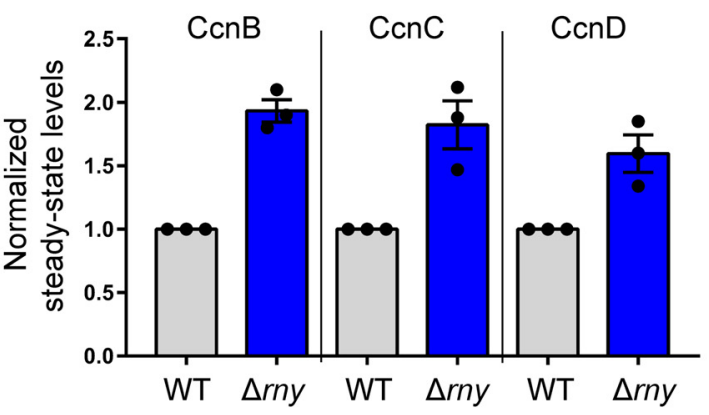

I

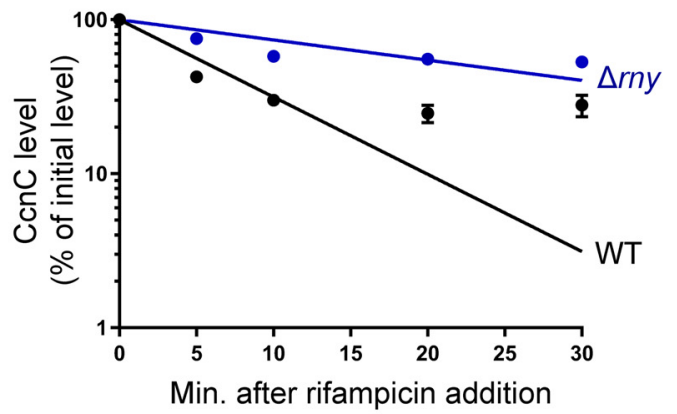

H

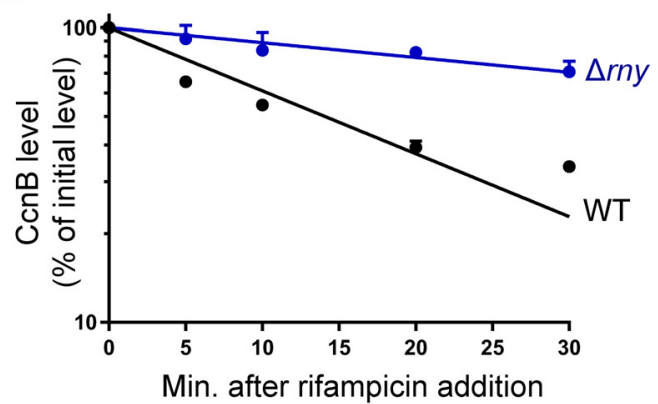

J

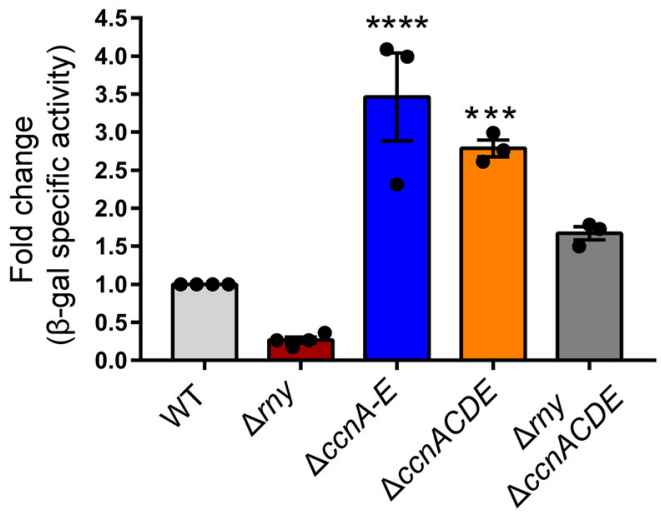

FIG 5 RNase $Y$ regulates Ccn sRNA stability and function in S. pneumoniae D39. (A and D) Read coverage maps of CcnA and CcnE in a $\Delta$ rny mutant (NRD10092) compared to the WT parent (IU1781). Track labels corresponding to read coverage maps are described in the legend to Fig. 4. (B, E, and G) $C \mathrm{cnA}, \mathrm{C} \mathrm{cnE}, \mathrm{CcnB}, \mathrm{C} \mathrm{cnC}$, and $\mathrm{C} \mathrm{cnD}$ steady-state levels were determined on Northern blots following extraction of RNA from exponentially growing cultures of a $\Delta$ rny mutant (NRD10092) and a WT parent strain (IU1781) as described in Materials and Methods. Signal intensities in the Northern blots were quantified and normalized to 5S RNA amount. (C, F, H, and I) RNA amount time course experiment to determine the intrinsic stability of CcnA, CcnE, CcnB, and CcnC in a $\Delta$ rny mutant (NRD10092) and the WT strain (IU1781) after treatment with rifampin to stop transcription, as described in Materials and Methods. Semilog sRNA decay curves were generated by fitting the normalized signal intensities determined on Northern blots for each time point sample. Points and error bars in the curves (where not 


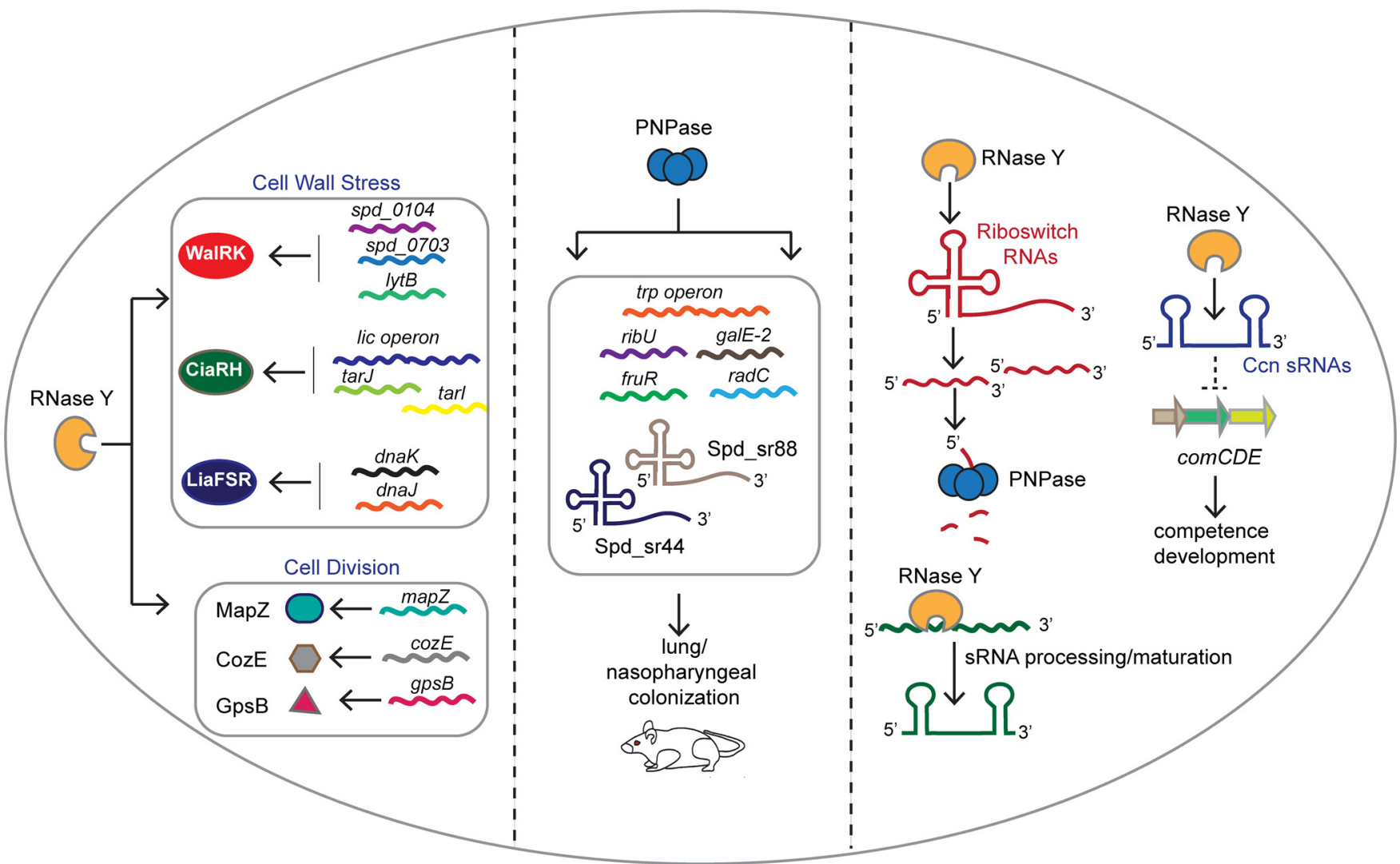

FIG 6 Summary of the major biological functions of RNase $Y$ and PNPase. (Left) RNase $Y$ regulates pneumococcal cell morphology by impacting transcripts encoding important cell division regulators. (Middle) PNPase mediates regulation of pneumococcal virulence gene expression. (Right) Roles of RNase $Y$ and PNPase in regulatory RNA decay and processing.

\section{DISCUSSION}

This paper is the first report of the global roles of two highly conserved Gram-positive RNases, RNase $\mathrm{Y}$ and PNPase, in the human pathogen S. pneumoniae (summarized in Fig. 6). The loss of RNase $Y$ significantly impacts gene expression by affecting $\sim 10 \%$ of the pneumococcal transcriptome and thereby causing pleiotropic phenotypes (Fig. 1A, C, and D; Fig. 2A and B; Fig. 3A and B; Tables 1 and 3). In contrast, PNPase exerts a relatively smaller impact on the transcriptome compared to RNase $Y$ but, interestingly, regulates the expression of specific transcripts previously implicated in pneumococcal virulence control (Tables 2 and 4; Fig. $2 C$ and D; Fig. 3C and D). Accordingly, the loss of PNPase severely attenuates S. pneumoniae virulence in vivo (Fig. 1E; Fig. S2A). This study also revealed that both RNase $\mathrm{Y}$ and PNPase work in concert to regulate the processing and decay of several regulatory RNAs, in particular, those characterized by the presence of 5' cis-acting regulatory elements (Fig. $3 \mathrm{~B}$ and D and 4; Fig. S3; Tables 2 and 4). In addition, RNase $Y$ stabilizes the conserved pneumococcal trans-acting sRNAs CcnA to -E, further impacting Ccn-mediated target gene regulation (Fig. 5).

RNase $\mathbf{Y}$ is a pleiotropic regulator in S. pneumoniae D39. Deletion of rny in S. pneumoniae leads to a $\sim 2$-fold increase in doubling time in vitro (Fig. 1A; Table S2),

FIG 5 Legend (Continued)

visible, error bars are smaller than the symbol) represent the means and SEM from at least three independent experiments. sRNA half-life measurements corresponding to RNA stability curves are listed in Table S4. $(J) \beta$-Galactosidase assay to determine the impact of RNase $Y$ on Ccn sRNA-mediated comC translational regulation. Expression of the comC-'lacZ translational fusion was monitored by $\beta$-galactosidase assays of samples removed from exponentially growing cultures of the unencapsulated D39 parent strain (NRD10041) and isogenic $\Delta c p s$ $\Delta$ rny comC-'lacZ (NRD10113), $\Delta c p s \quad \Delta c c n A-E$ comC'-lacZ (NRD10187), $\Delta c p s \quad \triangle c c n A C D E$ comC-'lacZ (NRD10054), and $\Delta c p s \quad \Delta r n y \Delta c c n A C D E$ comC-'IacZ (NRD10120) mutants. Bars and error bars represent means and SEM from at least three independent experiments. ${ }^{*}, P<0.05 ;{ }^{* *}$, $P<0.01 ;{ }^{* * *}, P<0.001 ;$ ns, not significant. 
similar to prior observations with $B$. subtilis and $C$. perfringens $(25,27)$, and interferes with pneumococcal cell division (Fig. 1C). We identified several important pneumococcal cell wall and division regulators, including mapZ (encoding a midcell anchor protein), cozE (encoding a coordinator of zonal division), and gpsB (encoding a regulator that balances septal and elongation peptidoglycan synthesis), as being significantly upregulated in a $\Delta$ rny mutant (Fig. 2B; Table 1). In S. pneumoniae, MapZ guides tubulin-like FtsZ protein from midcell rings of dividing cells to the equators of new daughter cells $(47,48)$, whereas GpsB and CozE are major peptidoglycan (PG) biosynthesis regulators that play distinct but crucial roles at the midcell to maintain the normal ovococcus shape of pneumococcus by modulating the activities of different penicillinbinding proteins (PBPs), which catalyze peptide cross-link formation in peptidoglycan (49-51). Accordingly, $\Delta$ mapZ mutants exhibit a variety of abnormal cell shapes and sizes, decreased cell viability, increased doubling time, and aberrant Fts $Z$ movement $(47,48,52)$, while cells depleted of gpsB or cozE form elongated cells that are unable to divide or form chains that round up and lyse, respectively $(49,51,53)$.

Several transcripts under the control of the essential TCS WaIRK and the TCSs LiaFSR and CiaRH are impacted in the $\Delta$ rny mutant (Table 1), again consistent with cell wall and surface stress in cells lacking RNase $Y$, as numerous proteins in these regulons are known to impact cell morphology and chaining (54-58). In this regard, the defects in cell shape and morphology observed for B. subtilis $\Delta$ rny mutants were attributed to the upregulation of several PG biosynthesis genes, including $\operatorname{rod} A(27)$. It remains to be determined what cell wall stress is caused by absence of pneumococcal RNase $Y$ and whether induction of certain proteins in these multiple surface stress TCS regulons can account for the defects in growth and morphology of the S. pneumoniae $\Delta$ rny mutant.

Besides responding to cell wall stress, the CiaRH TCS has been implicated in pneumococcal biofilm formation (59), competence (60), and virulence (61). In particular, the five conserved pneumococcal base-pairing sRNAs ( $C \mathrm{cnA}$ to $-\mathrm{E}$ ) negatively regulate translation of comC, which encodes the competence stimulatory peptide (42-44). We show here that RNase $Y$ functions as a critical regulator of Ccn sRNA stability and impacts Ccn-mediated negative regulation of competence development in S. pneumoniae (Fig. 5). Interestingly, the recent Grad-seq analysis indicated possible stable RNA-protein complexes between the $3^{\prime}$-to-5' exonuclease YhaM/Cbf1 and the Ccn sRNAs that were confirmed in pulldown experiments with Ccn sRNAs as bait in S. pneumoniae TIGR4 strain. In addition, CcnA to -E pulled down several degradosome components, including RNase J1/ J2 and PNPase (23). The Gram-positive specific Cbf1 exonuclease has been implicated in trimming single-stranded RNA tails at the $3^{\prime}$ ends of Rho-independent terminated transcripts $(16,17,23)$, thereby preventing decay by other exoribonucleases, such as PNPase and RNase R, that require an unstructured tail of 7 to 10 nucleotides (nt) for binding (17, 62). Although data presented here suggest that the Ccn sRNAs are targeted by RNase $Y$ (Fig. 5), RNase $Y$ was not identified as a strong Con sRNA interactor by Grad-seq (23), perhaps indicating complex dissociation during gradient centrifugation. Future experiments will determine whether Ccn sRNAs are direct substrates of RNase $Y$ and whether Cbf1mediated 3' trimming impacts Ccn sRNA decay by RNase Y. Moreover, results in this paper raise the important question of whether RNase $Y$ functions similarly to RNase $E$ in mediating decay of trans-acting sRNAs that form sRNA-mRNA base pairs in S. pneumoniae and other Gram-positive bacteria.

Finally, lack of RNase $Y$ affected the steady-state transcript levels of numerous key metabolic operons and known pneumococcal colonization and virulence factors, including pavB (fibronectin-binding protein and host interaction) (63), clpL (adaptor protein for ClpP protease) (64), CiaRH TCS regulon members (licC, licB, and licA [choline metabolism]) (65), LiaFSR TCS regulon members (dnaK and dnaJ [protein chaperones]) (66), WalRK TCS regulon members (lytB [glucosaminidase]), spd_0104 (LysM-domain protein) (35), and PnpRS TCS regulon members (phosphate uptake) $(35,67)$ (Table 1$)$. Thus, loss of RNase $Y$ clearly exerts a global impact on the pneumococcal transcriptome that broadly affects physiology, growth, and virulence. 
PNPase is a key regulator of S. pneumoniae D39 virulence. In contrast to the highly pleiotropic effects caused by the absence of RNase $Y$, the lack of PNPase minimally affected growth or morphology in vitro, but remarkably, caused strong attenuation in vivo (Fig. $1 \mathrm{~A}, \mathrm{~B}, \mathrm{C}$, and $\mathrm{E}$ ). The lack of phenotypes of the $\Delta p n p$ mutant in vitro may suggest that the pneumococcal $3^{\prime}-5^{\prime}$ exoribonuclease RNase $R$ can functionally bypass PNPase under certain experimental conditions. Notably, 10 of 20 protein-coding transcripts that were either upregulated (ribU $[\sim 4$-fold], fruR $[\sim 2$-fold], and galE-2 [ 2-fold]) or down-regulated (trpACDGE [ 2.5- to 4-fold]) in the $\triangle p n p$ mutant included metabolic genes implicated in nasopharyngeal colonization and/or lung infection in a mouse model (35) (Fig. 2C and D; Table 2). The relative level of the full-length transcript of the T-box riboswitch Spd-sr88 located within the 5' UTR of the trp operon (Fig. 4A) also decreased by $\sim 2$-fold in the $\Delta p n p$ mutant, with concomitant accumulation of $s p d$ sr88-derived decay intermediates (Fig. 4B; Table 4). These decay products are likely generated by RNase $\mathrm{Y}$ cleavage, since the relative full-length Spd-sr88 transcript levels increase by $\sim 11$-fold in a $\Delta$ rny mutant (Fig. 4B; Fig. S5).

We do not yet know how PNPase positively regulates the trp operon in S. pneumoniae, but in general, trp operon regulation is important and complex in different bacteria and often involves RNA-based posttranscriptional mechanisms (68). For example, in $B$. subtilis under tryptophan-replete conditions, trp expression is repressed as a consequence of TRAP regulator protein-mediated transcription termination of the trp leader, which is subsequently degraded by RNase $\mathrm{Y}$ and/or J1 and PNPase. (69). In E. coli, tryptophan synthesis is regulated by a classical transcription attenuation mechanism, where under tryptophan-replete conditions, the upstream $\operatorname{trpL}$ leader peptide ( $\operatorname{TrpL}$ ) is translated efficiently, allowing formation of a terminator stem-loop that stops transcription before the downstream trp genes (70). Recently, the terminated trpL RNA generated by this attenuation mechanism was shown to function in Sinorhizobium meliloti as a base-pairing sRNA to destabilize several transcripts, including that of the trp biosynthesis genes (71). Likewise, previous studies in important Gram-positive pathogens, including Listeria monocytogenes and Enterococcus faecalis, show that terminated riboswitches are not "junk RNA" but function as mRNA- or protein-binding regulatory RNAs $(72,73)$. S. pneumoniae does not possess obvious homologs of TRAP or TrpL, but its trp operon instead contains the T-box (tRNA-sensing structure) riboswitch Spd-sr88. Whether the RNA decay products derived from spd-sr88 (Fig. 4B) function as regulatory RNAs to destabilize the trp operon transcript in a $\Delta p n p$ mutant awaits further investigation. These combined results show that PNPase controls the transcript amounts of numerous genes required for pneumococcal pathogenesis, including the trp operon and the riboswitches Spd-sr88 and Spd-sr44 (Fig. 4B and E; Fig. S5; Tables 2 and 4) $(35,46)$, supporting the notion that PNPase is a key regulator of S. pneumoniae pathogenesis.

RNase $\mathrm{Y}$ and PNPase play roles in SRNA processing and decay in S. pneumoniae D39. Riboswitch turnover is important for recycling of the ligands to which they respond, and a role for RNase $Y$ in this process was reported in $B$. subtilis $(11,74)$ and $S$. aureus (21). Here, we show that pneumococcal RNase $Y$ mediates the initial endoribonucleolytic cleavage of $5^{\prime}$ cis-acting regulatory elements, which are subsequently degraded by PNPase. Likewise, in a $\Delta p n p$ mutant, we found that decay intermediates of eight riboswitch RNAs accumulated, while their corresponding full-length transcripts increased in abundance in the absence of RNase Y (Fig. 4; Fig. S3 and S5; Tables 3 and 4). These observations are consistent with a recent study in S. pyogenes showing that the coordinated actions of RNase $Y$ and PNPase play a crucial role in the decay of riboswitches (20). In addition, our data indicate that RNase $Y$ likely generates some sRNAs by cleaving larger transcripts, as observed for Spd-sr88 and Spd-sr116 (Fig. 4; Fig. S3 and S5). We conclude that RNase $Y$ and PNPase work in tandem to degrade pneumococcal cis-acting regulatory RNAs, while RNase $Y$ also plays an important role in sRNA processing and maturation. Whether RNase $Y$ and PNPase interact together in a degradosome-like complex to impact regulatory RNA levels in S. pneumoniae will be resolved in future experiments. 


\section{MATERIALS AND METHODS}

Bacterial strains and growth conditions. Bacterial strains used in this study were derived from encapsulated S. pneumoniae serotype 2 strain D39W and are listed in Table S1. Strains were grown on plates containing Trypticase soy agar II (modified; Becton Dickinson [BD]) and 5\% (vol/vol) defibrinated sheep blood (TSAll BA) at $37^{\circ} \mathrm{C}$ in an atmosphere of $5 \% \mathrm{CO}_{2}$. Liquid cultures were grown statically in $\mathrm{BD}$ brain heart infusion (BHI) broth at $37^{\circ} \mathrm{C}$ in an atmosphere of $5 \% \mathrm{CO}_{2}$. Bacteria were inoculated into $\mathrm{BHI}$ broth from frozen cultures or single colonies. For overnight cultures, strains were first inoculated into 17$\mathrm{mm}$-diameter polystyrene plastic tubes containing $5 \mathrm{ml}$ of $\mathrm{BHI}$ broth and then serially diluted 100-fold into five tubes; these cultures were then grown for 10 to $16 \mathrm{~h}$. Cultures with an $\mathrm{OD}_{620}$ of 0.1 to 0.4 were diluted to a starting $\mathrm{OD}_{620}$ between 0.002 and 0.005 in $5 \mathrm{ml}$ of $\mathrm{BH}$ broth in 16-mm glass tubes. Growth was monitored by measuring $\mathrm{OD}_{620}$ using a Spectronic 20 spectrophotometer. For antibiotic selections, TSAll BA plates and BHI cultures were supplemented with $250 \mu \mathrm{g} / \mathrm{ml}$ kanamycin or $150 \mu \mathrm{g} / \mathrm{ml}$ streptomycin.

Construction and verification of mutants. Mutant strains were constructed by transformation of competent S. pneumoniae strains with linear PCR amplicons as described previously (75). DNA amplicons containing antibiotic resistance markers were synthesized by overlapping fusion PCR. S. pneumoniae cells were induced to competence by the addition of synthetic competence stimulatory peptide 1 (CSP1; Anaspec, Inc.). Markerless deletions and replacements of target genes were constructed using the $\mathrm{Kan}^{\mathrm{r}} \mathrm{rpsL}^{+}$(Janus cassette) allele replacement method as described previously (76). In the first step, the Janus cassette was used to disrupt target genes in an $r p s L 1$ (Str ${ }^{r}$ ) strain background, and transformants were screened for kanamycin resistance and streptomycin sensitivity. In the second step, the Janus cassette was replaced by a PCR amplicon containing the desired mutation or replacement lacking antibiotic markers, and the resulting transformants were screened for streptomycin resistance and kanamycin sensitivity. Final transformants were isolated as single colonies three times on TSAll BA plates containing antibiotics listed in Table S1 and subsequently grown for storage in BHI containing the appropriate antibiotic. All constructs were confirmed by PCR amplification and sequencing.

Microscopy. After cultures reached an $\mathrm{OD}_{620}$ of $\sim 0.1$ to $0.2,1 \mathrm{ml}$ was removed and centrifuged at $16,000 \times g$ for $2 \mathrm{~min}$ at room temperature. Pellets were suspended in $50 \mu \mathrm{l}$ of $\mathrm{BHI}$ broth. Cells were examined using either a Nikon E200 or a Leica DM 1000 LED phase-contrast microscope, and images were captured using a Nikon DS-Fi3 or a Leica ICC50W camera, respectively. A total of over 100 chains from each of two independent cultures of each strain were counted to determine distributions of numbers of cells per chain.

RNA extraction. RNA for high-throughput sequencing was prepared as described previously (77). Briefly, strains were grown in $30 \mathrm{ml}$ of $\mathrm{BHI}$ starting at an $\mathrm{OD}_{620}$ of 0.002 in $50-\mathrm{ml}$ conical tubes. RNA was extracted from exponentially growing cultures of IU3116 (wild-type parent; D39 rpsL1 CEP::kan rpsL ${ }^{+}$) and its derived isogenic mutants IU5498 (D39 rpsL1 1 pnp CEP::kan rpsL ${ }^{+}$) and IU5504 (D39 rpsL1 $\Delta$ rny CEP::kan $r p s L^{+}$) at an $\mathrm{OD}_{620}$ of $\sim 0.1$ from matched batches of BHI broth for mRNA-seq analysis or from IU1781 (wild-type parent; D39 rpsL1) and its derived markerless mutants IU4883 (D39 rpsL1 $\Delta p n p$ ) and NRD10092 (D39 rpsL1 $\Delta$ rny) at an $\mathrm{OD}_{620}$ of $\sim 0.15$ for sRNA-seq analysis using the FastRNA Pro Blue kit (MP Bio) according to the manufacturer's guidelines. RNA extracted for mRNA-seq analysis was purified with an miRNeasy minikit (Qiagen), which included an on-column DNase I (Qiagen) treatment. For sRNA-seq analysis, RNA was alcohol precipitated following extraction and subsequently subjected to DNase treatment (Turbo DNase; Ambion) following the manufacturer's protocol. Sample mixtures (total reaction volume of $50 \mu \mathrm{l}$ ) were incubated with Turbo DNase for $30 \mathrm{~min}$ at $37^{\circ} \mathrm{C}$, and each reaction was stopped by addition of $150 \mu \mathrm{l}$ of diethyl pyrocarbonate (DEPC)-treated water and $200 \mu \mathrm{l}$ of neutral phenol-chloroform-isoamyl alcohol (Fisher). DNase-treated RNA samples were phenol extracted and alcohol precipitated. To isolate RNA for droplet digital PCR, RNA was extracted from exponential-growth-phase cultures following the procedure described above for sRNA-seq analysis. The amount and purity of all RNA samples isolated were assessed by NanoDrop spectroscopy (Thermo Fisher). RNA integrity of the samples used for RNA-seq library preparation was further assessed using the Agilent 2100 Bioanalyzer (Agilent Technologies).

Library preparation and mRNA-seq. CDNA libraries were prepared from total RNA by the University of Wisconsin-Madison Biotechnology Center as described previously (40). Briefly, total RNA was subjected to rRNA depletion using a RiboZero rRNA removal kit (Epicentre, Inc., Madison, WI, USA). Double-stranded cDNA synthesis was performed with rRNA-depleted mRNA using a ScriptSeq v2 RNA-seq library preparation kit (Epicentre, Inc., Madison, WI, USA) in accordance with the manufacturer's standard protocol. The amplified libraries were purified using Agencourt AMPure XP beads. Quality and quantity were assessed using an Agilent DNA 1000 chip (Agilent Technologies, Inc., Santa Clara, CA, USA) and a Qubit double-stranded DNA (dsDNA) High Sensitivity assay kit (Invitrogen, Carlsbad, CA, USA), respectively. Libraries were standardized to $2 \mu \mathrm{M}$ and cluster generation was performed using standard Cluster kits (v3) and Illumina Cluster Station. Single-end 100-bp sequencing was performed using standard SBS (sequencing by synthesis) chemistry (v3) on an Illumina HiSeq2000 sequencer. Images were analyzed using the standard Illumina pipeline, version 1.8.2.

Library preparation and sRNA-seq. sRNA libraries were prepared from total RNA as described previously (40). Briefly, $5 \mu \mathrm{g}$ of DNase-treated total RNA was subjected to rRNA removal (RiboZero rRNA removal for Gram-positive bacteria; Illumina). rRNA-depleted samples were then subjected to RNA fragmentation using the Ambion RNA fragmentation kit (AM8740). Fragmented RNA was subjected to RNA $5^{\prime}$-polyphosphatase (Epicenter) treatment, which was performed to facilitate the $5^{\prime}$-adapter ligation step. Small RNA libraries were generated by Macrogen using the TruSeq small RNA library kit (Illumina). Then, 100-bp paired-end read sequencing was performed using an Illumina HiSeq2000 sequencer.

RNA-seq analysis. Raw sequencing reads from mRNA-seq were quality and adapter trimmed using Trimmomatic version 0.17 (78) with a minimum length of 90, while those corresponding to sRNA-seq were preprocessed for alignment with Cutadapt. The trimmed reads were mapped on the Streptococcus 
pneumoniae D39 (RefSeq NC_008533) genome and D39 plasmid pDP1 sequence (RefSeq NC_005022) using Bowtie2 (79). mRNA-seq and sRNA-seq analysis were performed as described previously using DESeq2 (77). Genes were defined as differentially expressed if their $P_{\text {adj }}(P$ value adjusted for multiple testing) was $<0.005$. Primary data from mRNA-seq and sRNA-seq analyses was submitted to the NCBI Gene Expression Omnibus (GEO). The accession numbers for the sRNA-seq data corresponding to wild-type samples used for comparison of $\Delta r n y$ and $\Delta p n p$ mutants are GSE148867 and GSE123437, respectively.

ddPCR analysis. One microgram of DNA-free RNA was reverse transcribed using random hexamers and Superscript III reverse transcriptase (RT) (Invitrogen) following the manufacturer's protocol. For each

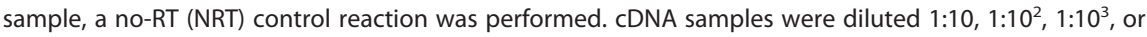
1:10 ${ }^{6}$, and $2 \mu \mathrm{l}$ of each diluted RT and NRT PCR sample was added to a $22-\mu \mathrm{l}$ reaction mixture containing $11 \mu \mathrm{l}$ of QX200 ddPCR EvaGreen Supermix (Bio-Rad) and $1.1 \mu \mathrm{l}$ of each ddPCR primer, each at $2 \mu \mathrm{M}$ (Table S3). A single no-template control (NTC) for each ddPCR primer pair used in this study was included. Droplet generation from each reaction mixture was achieved via the QX200 automated droplet generator (Bio-Rad), and endpoint PCR was performed using a thermal cycler following the instructions from the manufacturer. A QX200 droplet reader (Bio-Rad) was used to analyze droplets from each individual reaction mixture, where PCR-positive and PCR-negative droplets were counted to provide absolute quantification of the target transcript. Data analysis was performed with QuantaSoft software (Bio-Rad), and the concentration of each target is expressed as copies per microliter. Reactions were performed using CDNA from at least three independent biological replicates, and transcript copies were normalized to $16 \mathrm{~S}$ rRNA (internal control). Normalized transcript copy numbers were used to calculate fold changes of transcripts corresponding to target genes in different sets of mutants relative to the WT parent. Statistical analysis was performed using Student's $t$ test in GraphPad Prism version 7.0.

RNA stability assay. To determine RNA stabilities, cultures were grown in BHI to exponential phase $\left(\mathrm{OD}_{620} \approx 0.15\right)$ as described above, and a culture sample $\left(0 \mathrm{~h}\right.$ after the end of log-phase growth $\left.\left[T_{0}\right]\right)$ was collected. Rifampin was added to inhibit transcription, and additional samples were collected 5, 10, 20, and $30 \mathrm{~min}$ after rifampin addition. All samples were subjected to hot phenol lysis as described previously (80). Briefly, $700 \mu \mathrm{l}$ of sample was added to a mixture containing $800 \mu \mathrm{l}$ of acid phenolchloroform-isoamyl alcohol, pH 4.3 (Fisher Scientific), and $100 \mu$ l of lysis buffer ( $320 \mathrm{mM}$ sodium acetate [pH 4.6], 8\% [wt/vol] SDS, and $16 \mathrm{mM}$ EDTA) equilibrated to $65^{\circ} \mathrm{C}$. Samples were mixed at $65^{\circ} \mathrm{C}$ for $5 \mathrm{~min}$ and centrifuged for $30 \mathrm{~min}$ at $4^{\circ} \mathrm{C}$ to separate phases. The upper aqueous phase was extracted a second time with an equal volume of neutral phenol-chloroform-isoamyl alcohol, pH 6.7 (Fisher Scientific). RNA was ethanol precipitated and resuspended in DEPC-treated water. RNA concentration was measured using a NanoDrop 2000 (Thermo Fisher Scientific).

Northern blot analysis. Two micrograms of each RNA sample was loaded on 10\% polyacrylamide gels containing $7 \mathrm{M}$ urea or loaded onto $10 \%$ Criterion TBE-urea precast gels (Bio-Rad) and electrophoresed at 85 V. RNA samples were transferred to a Zeta-Probe GT membrane (Bio-Rad) using a Trans-Blot SD semidry transfer apparatus (Bio-Rad) following the manufacturer's guidelines. Transferred RNA was UV cross-linked and hybridized overnight with $100 \mathrm{ng} / \mathrm{ml}$ of $5^{\prime}$ biotinylated DNA probe (Table S3) in Ultrahyb (Ambion) hybridization buffer at $42^{\circ} \mathrm{C}$. Blots were developed using a BrightStar BioDetect kit protocol (Ambion), imaged with a ChemiDoc MP imager (Bio-Rad), and quantified using Image Lab software version 5.2.1 (Bio-Rad). Signal intensity corresponding to each sRNA was normalized to that of $5 \mathrm{~S}$ rRNA, which served as an internal loading control. Decay curves corresponding to RNA stability time course experiments were generated by using GraphPad Prism version 7.0.

Mouse models of infection. All procedures were approved in advance by the Bloomington Institutional Animal Care and Use Committee (BIACUC) or UTHealth Animal Welfare Committee and were performed according to recommendations of the National Research Council. Experiments were performed as described in reference 76, with the following changes. Male ICR mice (21 to $24 \mathrm{~g}$; Harlan) were anesthetized by inhaling 4\% isoflurane (Butler Animal Health Supply) for $8 \mathrm{~min}$. In two independent experiments, a total of 8 mice were intranasally inoculated with each bacterial strain to be tested. Bacteria were grown exponentially in $\mathrm{BHI}$ broth in an atmosphere of $5 \% \mathrm{CO}_{2}$ to an $\mathrm{OD}_{620}$ of $\sim 0.1$. Ten milliliters of culture was centrifuged for $5 \mathrm{~min}$ at $14,500 \times g$ and then suspended in $1 \mathrm{ml} 1 \times$ PBS to yield $\sim 10^{7} \mathrm{CFU} \mathrm{ml}{ }^{-1}$. CFU counts were determined by serial dilution and plating. Fifty microliters of suspensions was administered intranasally as described previously (75). Mice were monitored visually at 4- to 8-h intervals, and moribund mice were euthanized by $\mathrm{CO}_{2}$ asphyxiation followed by cervical dislocation (IU-Bloomington), which was used as the time of death in statistical analyses. Alternatively, isoflurane-anesthetized moribund mice were euthanized by cardiac puncture-induced exsanguination followed by cervical dislocation (UTHealth). Kaplan-Meir survival curves and log-rank tests were generated using GraphPad Prism 7.0 software.

$\boldsymbol{\beta}$-Galactosidase assays. Strains containing the $\operatorname{com} C-1 / a c Z$ translational fusion were grown in BHI broth to exponential phase $\left(\mathrm{OD}_{620} \approx 0.15\right)$. Samples were taken from each culture and assayed for $\beta$-galactosidase activity as described by Miller (81), with slight modifications. Briefly, $1 \mathrm{ml}$ of culture was removed and centrifuged at $16,000 \times \mathrm{g}$ for $2 \mathrm{~min}$ at $4^{\circ} \mathrm{C}$. Pellets were resuspended in $1 \mathrm{ml}$ of Z-buffer containing 2$\beta$-mercaptoethanol at a final concentration of $0.27 \%$. Each sample mixture was lysed by subsequent incubation at $37^{\circ} \mathrm{C}$ for $10 \mathrm{~min}$ following the addition of $10 \mu \mathrm{l}$ of $5 \%$ ( $\mathrm{vol} / \mathrm{vol}$ ) Triton. One hundred microliters of lysed culture samples was then assayed for $\beta$-galactosidase specific activity as described previously (81).

Competence assays. Overnight cultures of strains were diluted into $5 \mathrm{ml}$ of $\mathrm{C}+\mathrm{Y}$ medium (caseinbased medium supplemented with yeast extract), $\mathrm{pH} 8$ (7), to a starting $\mathrm{OD}_{620}$ of $\sim 0.002$. Starting from the initial inoculation and at 1-h intervals thereafter, $1 \mathrm{ml}$ of a cell suspension was removed and mixed with $50 \mathrm{ng}$ of amplicon DNA carrying a kanamycin resistance marker. After incubation for $90 \mathrm{~min}$ at $37^{\circ} \mathrm{C}$ in an atmosphere of $5 \% \mathrm{CO}_{2}$, samples were serially diluted and plated on blood agar plates containing $250 \mu \mathrm{g} /$ $\mathrm{ml}$ kanamycin and on blood agar plates without antibiotics to determine transformant CFU and total viable 
CFU, respectively. The transformation frequency (TF) was determined as the ratio of $\mathrm{Kan}^{r}$ CFU to total CFU per unit volume of cell suspension. Under these culture conditions, the natural transformation frequency of the wild-type strain followed a reproducible pattern with time in culture, with a high peak $\left(2 \times 10^{-5}\right)$ about $2 \mathrm{~h}$ after inoculation $\left(\mathrm{OD}_{620}=0.02\right.$ to 0.03$)$. Accordingly, the natural transformation frequencies of the $\Delta r n y$ mutant and wild-type strains were determined around an optical density of $\sim 0.02$ to 0.03 .

Data availability. The sRNA-seq data corresponding to $\Delta r n y$ and $\Delta p n p$ mutants and the mRNA-seq data corresponding to all strains have been deposited in GEO under the accession number GSE173392.

\section{SUPPLEMENTAL MATERIAL}

Supplemental material is available online only.

FIG S1, TIF file, 1.6 MB.

FIG S2, TIF file, 0.3 MB.

FIG S3, TIF file, 2.3 MB.

FIG S4, TIF file, 0.5 MB.

FIG S5, TIF file, 1.5 MB.

FIG S6, TIF file, 2.4 MB.

TABLE S1, XLSX file, $0.02 \mathrm{MB}$.

TABLE S2, XLSX file, 0.01 MB.

TABLE S3, XLSX file, $0.01 \mathrm{MB}$.

TABLE S4, XLSX file, 0.01 MB.

\section{ACKNOWLEDGMENTS}

We thank Doug Rusch (Indiana University Bloomington) for assistance with Illumina mRNA-Seq analyses and Todd Cameron for help with R-scripts.

This work was supported by the McGovern Medical Startup funds and NIGMS grant R01GM121368 (to D.S., J.F., K.C., and N.R.D.) and NIGMS grant R35GM131767 (to M.E.W.).

Study designed by D.S., M.E.W., and N.R.D.; experiments carried out by D.S., J.F., K.C., and N.R.D.; analysis done by D.S., J.F., and N.R.D.; and paper written by D.S., M.E.W., and N.R.D.

\section{REFERENCES}

1. Marks LR, Davidson BA, Knight PR, Hakansson AP. 2013. Interkingdom signaling induces Streptococcus pneumoniae biofilm dispersion and transition from asymptomatic colonization to disease. mBio 4:e00438-13. https://doi .org/10.1128/mBio.00438-13.

2. Pettigrew MM, Marks LR, Kong Y, Gent JF, Roche-Hakansson H, Hakansson AP. 2014. Dynamic changes in the Streptococcus pneumoniae transcriptome during transition from biofilm formation to invasive disease upon influenza A virus infection. Infect Immun 82:4607-4619. https://doi.org/ 10.1128/IAI.02225-14

3. GBD 2016 Lower Respiratory Infections Collaborators. 2018. Estimates of the global, regional, and national morbidity, mortality, and aetiologies of lower respiratory infections in 195 countries, 1990-2016: a systematic analysis for the Global Burden of Disease Study 2016. Lancet Infect Dis 18: 1191-1210. https://doi.org/10.1016/S1473-3099(18)30310-4.

4. Ogunniyi AD, Mahdi LK, Trappetti C, Verhoeven N, Mermans D, Van der Hoek MB, Plumptre CD, Paton JC. 2012. Identification of genes that contribute to the pathogenesis of invasive pneumococcal disease by in vivo transcriptomic analysis. Infect Immun 80:3268-3278. https://doi.org/10 .1128/IAI.00295-12.

5. D'Mello A, Riegler AN, Martínez E, Beno SM, Ricketts TD, Foxman EF, Orihuela CJ, Tettelin H. 2020. An in vivo atlas of host-pathogen transcriptomes during Streptococcus pneumoniae colonization and disease. Proc Natl Acad Sci U S A 117:33507-33518. https://doi.org/10.1073/pnas 2010428117.

6. Song X-M, Connor W, Hokamp K, Babiuk LA, Potter AA. 2009. Transcriptome studies on Streptococcus pneumoniae, illustration of early response genes to THP-1 human macrophages. Genomics 93:72-82. https://do .org/10.1016/j.ygeno.2008.09.008.

7. Aprianto R, Slager J, Holsappel S, Veening J-W. 2016. Time-resolved dual RNA-seq reveals extensive rewiring of lung epithelial and pneumococcal transcriptomes during early infection. Genome Biol 17:198. https://doi .org/10.1186/s13059-016-1054-5.
8. Song X-M, Connor W, Hokamp K, Babiuk LA, Potter AA. 2008. Streptococcus pneumoniae early response genes to human lung epithelial cells. BMC Res Notes 1:64. https://doi.org/10.1186/1756-0500-1-64.

9. Trinquier A, Durand S, Braun F, Condon C. 2020. Regulation of RNA processing and degradation in bacteria. Biochim Biophys Acta Gene Regul Mech 1863:194505. https://doi.org/10.1016/j.bbagrm.2020.194505.

10. Mohanty BK, Kushner SR. 2018. Enzymes involved in posttranscriptional RNA metabolism in Gram-negative bacteria. Microbiol Spectr 6:RWR0011-2017. https://doi.org/10.1128/microbiolspec.RWR-0011-2017.

11. Shahbabian K, Jamalli A, Zig L, Putzer H. 2009. RNase $Y$, a novel endoribonuclease, initiates riboswitch turnover in Bacillus subtilis. EMBO J 28 3523-3533. https://doi.org/10.1038/emboj.2009.283.

12. Lehnik-Habrink M, Schaffer M, Mäder U, Diethmaier C, Herzberg C, Stülke J. 2011. RNA processing in Bacillus subtilis: identification of targets of the essential RNase Y. Mol Microbiol 81:1459-1473. https://doi.org/10.1111/j .1365-2958.2011.07777.x.

13. Hunt A, Rawlins JP, Thomaides HB, Errington J. 2006. Functional analysis of 11 putative essential genes in Bacillus subtilis. Microbiology (Reading) 152:2895-2907. https://doi.org/10.1099/mic.0.29152-0.

14. Commichau FM, Rothe FM, Herzberg C, Wagner E, Hellwig D, Lehnik-Habrink M, Hammer E, Völker U, Stülke J. 2009. Novel activities of glycolytic enzymes in Bacillus subtilis: interactions with essential proteins involved in mRNA processing. Mol Cell Proteomics 8:1350-1360. https://doi.org/10.1074/mcp M800546-MCP200

15. Mäder U, Zig L, Kretschmer J, Homuth G, Putzer H. 2008. mRNA processing by RNases $\mathrm{J} 1$ and $\mathrm{J} 2$ affects Bacillus subtilis gene expression on a global scale. Mol Microbiol 70:183-196. https://doi.org/10.1111/j.1365 $-2958.2008 .06400 . x$.

16. Oussenko IA, Abe T, Ujiie H, Muto A, Bechhofer DH. 2005. Participation of 3 '-to-5' exoribonucleases in the turnover of Bacillus subtilis mRNA. J Bacteriol 187:2758-2767. https://doi.org/10.1128/JB.187.8.2758-2767.2005. 
17. Lécrivain $A-L$, Le Rhun $A$, Renault $\Pi$, Ahmed-Begrich $R$, Hahnke $K$, Charpentier E. 2018. In vivo 3'-to-5' exoribonuclease targetomes of Streptococcus pyogenes. Proc Natl Acad Sci U S A 115:11814-11819. https:// doi.org/10.1073/pnas.1809663115.

18. Liu B, Deikus G, Bree A, Durand S, Kearns DB, Bechhofer DH. 2014. Global analysis of mRNA decay intermediates in Bacillus subtilis wild-type and polynucleotide phosphorylase-deletion strains. Mol Microbiol 94:41-55. https://doi.org/10.1111/mmi.12748.

19. Anderson KL, Dunman PM. 2009. Messenger RNA turnover processes in Escherichia coli, Bacillus subtilis, and emerging studies in Staphylococcus aureus. Int J Microbiol 2009:525491. https://doi.org/10.1155/2009/525491.

20. Broglia L, Lécrivain A-L, Renault TT, Hahnke K, Ahmed-Begrich R, Le Rhun A, Charpentier E. 2020. An RNA-seq based comparative approach reveals the transcriptome-wide interplay between $3^{\prime}$-to- $5^{\prime}$ exoRNases and RNase Y. Nat Commun 11:1587. https://doi.org/10.1038/s41467-020-15387-6.

21. Khemici V, Prados J, Linder P, Redder P. 2015. Decay-initiating endoribonucleolytic cleavage by RNase $\mathrm{Y}$ is kept under tight control via wequence preference and sub-cellular localisation. PLoS Genet 11:e1005577. https://doi .org/10.1371/journal.pgen.1005577.

22. Durand S, Condon C. 2018. RNases and helicases in Gram-positive bacteria Microbiol Spectr 6:RWR-0003-2017. https://doi.org/10.1128/microbiolspec RWR-0003-2017.

23. Hör J, Garriss G, Di Giorgio S, Hack L-M, Vanselow JT, Förstner KU, Schlosser A, Henriques-Normark B, Vogel J. 2020. Grad-seq in a Gram-positive bacterium reveals exonucleolytic sRNA activation in competence control. EMBO J 39:e103852. https://doi.org/10.15252/embj.2019103852.

24. Durand $S$, Gilet $L$, Bessières $P$, Nicolas $P$, Condon C. 2012. Three essential ribonucleases-RNase $Y, J 1$, and III-control the abundance of a majority of Bacillus subtilis mRNAs. PLoS Genet 8:e1002520. https://doi.org/10 .1371 /journal.pgen.1002520.

25. Obana N, Nakamura K, Nomura N. 2017. Role of RNase $Y$ in Clostridium perfringens mRNA decay and processing. J Bacteriol 199:e00703-16. https://doi.org/10.1128/JB.00703-16.

26. Chen Z, Itzek A, Malke H, Ferretti JJ, Kreth J. 2013. Multiple roles of RNase $\mathrm{Y}$ in Streptococcus pyogenes mRNA processing and degradation. J Bacteriol 195:2585-2594. https://doi.org/10.1128/JB.00097-13.

27. Figaro S, Durand S, Gilet L, Cayet N, Sachse M, Condon C. 2013. Bacillus subtilis mutants with knockouts of the genes encoding ribonucleases RNase $\mathrm{Y}$ and RNase $\mathrm{J} 1$ are viable, with major defects in cell morphology, sporulation, and competence. J Bacteriol 195:2340-2348. https://doi.org/ 10.1128/JB.00164-13.

28. Kang SO, Caparon MG, Cho KH. 2010. Virulence gene regulation by CvfA, a putative RNase: the CvfA-enolase complex in Streptococcus pyogenes links nutritional stress, growth-phase control, and virulence gene expression. Infect Immun 78:2754-2767. https://doi.org/10.1128/IAI.01370-09.

29. Marincola G, Schäfer T, Behler J, Bernhardt J, Ohlsen K, Goerke C, Wolz C. 2012. RNase $Y$ of Staphylococcus aureus and its role in the activation of virulence genes. Mol Microbiol 85:817-832. https://doi.org/10.1111/j .1365-2958.2012.08144.x.

30. Cameron TA, Matz LM, De Lay NR. 2018. Polynucleotide phosphorylase: not merely an RNase but a pivotal post-transcriptional regulator. PLoS Genet 14:e1007654. https://doi.org/10.1371/journal.pgen.1007654.

31. Wang W, Bechhofer DH. 1996. Properties of a Bacillus subtilis polynucleotide phosphorylase deletion strain. J Bacteriol 178:2375-2382. https://doi .org/10.1128/jb.178.8.2375-2382.1996.

32. Barendt SM, Land AD, Sham L-T, Ng W-L, Tsui H-CT, Arnold RJ, Winkler ME. 2009. Influences of capsule on cell shape and chain formation of wild-type and pcsB mutants of serotype 2 Streptococcus pneumoniae. J Bacteriol 191:3024-3040. https://doi.org/10.1128/JB.01505-08.

33. Kaito C, Kurokawa K, Matsumoto Y, Terao Y, Kawabata S, Hamada S, Sekimizu K. 2005. Silkworm pathogenic bacteria infection model for identification of novel virulence genes. Mol Microbiol 56:934-944. https://doi .org/10.1111/j.1365-2958.2005.04596.x.

34. Numata S, Nagata M, Mao H, Sekimizu K, Kaito C. 2014. CvfA protein and polynucleotide phosphorylase act in an opposing manner to regulate Staphylococcus aureus virulence. J Biol Chem 289:8420-8431. https://doi .org/10.1074/jbc.M114.554329.

35. van Opijnen T, Camilli A. 2012. A fine scale phenotype-genotype virulence map of a bacterial pathogen. Genome Res 22:2541-2551. https://doi.org/ 10.1101/gr.137430.112.

36. Le Rhun A, Beer YY, Reimegård J, Chylinski K, Charpentier E. 2016. RNA sequencing uncovers antisense RNAs and novel small RNAs in Streptococcus pyogenes. RNA Biol 13:177-195. https://doi.org/10.1080/15476286 .2015.1110674.
37. Le Scornet A, Redder P. 2019. Post-transcriptional control of virulence gene expression in Staphylococcus aureus. Biochim Biophys Acta Gene Regul Mech 1862:734-741. https://doi.org/10.1016/j.bbagrm.2018.04.004.

38. De Lay N, Gottesman S. 2011. Role of polynucleotide phosphorylase in sRNA function in Escherichia coli. RNA 17:1172-1189. https://doi.org/10 .1261/rna.2531211.

39. Andrade JM, Pobre V, Matos AM, Arraiano CM. 2012. The crucial role of PNPase in the degradation of small RNAs that are not associated with Hfq. RNA 18:844-855. https://doi.org/10.1261/rna.029413.111.

40. Sinha D, Zimmer K, Cameron TA, Rusch DB, Winkler ME, De Lay NR. 2019 Redefining the sRNA transcriptome in Streptococcus pneumoniae serotype 2 strain D39. J Bacteriol 201:e00764-18. https://doi.org/10.1128/JB .00764-18.

41. Tsui HCT, Mukherjee D, Ray VA, Sham LT, Feig AL, Winkler ME. 2010. Identification and characterization of noncoding small RNAs in Streptococcus pneumoniae serotype 2 strain D39. J Bacteriol 192:264-279. https://doi .org/10.1128/JB.01204-09.

42. Slager J, Aprianto R, Veening J-W. 2018. Deep genome annotation of the opportunistic human pathogen Streptococcus pneumoniae D39. Nucleic Acids Res 46:9971-9989. https://doi.org/10.1093/nar/gky725.

43. Kumar R, Shah P, Swiatlo E, Burgess SC, Lawrence ML, Nanduri B. 2010. Identification of novel non-coding small RNAs from Streptococcus pneumoniae TIGR4 using high-resolution genome tiling arrays. BMC Genomics 11:350. https://doi.org/10.1186/1471-2164-11-350.

44. Acebo P, Martin-Galiano AJ, Navarro S, Zaballos A, Amblar M. 2012. Identification of 88 regulatory small RNAs in the TIGR4 strain of the human pathogen Streptococcus pneumoniae. RNA 18:530-546. https://doi.org/ 10.1261/rna.027359.111

45. Warrier I, Ram-Mohan N, Zhu Z, Hazery A, Echlin H, Rosch J, Meyer MM, van Opijnen T. 2018. The transcriptional landscape of Streptococcus pneumoniae TIGR4 reveals a complex operon architecture and abundant riboregulation critical for growth and virulence. PLoS Pathog 14: e1007461. https://doi.org/10.1371/journal.ppat.1007461.

46. Mann B, van Opijnen T, Wang J, Obert C, Wang Y-D, Carter R, McGoldrick DJ, Ridout G, Camilli A, Tuomanen El, Rosch JW. 2012. Control of virulence by small RNAs in Streptococcus pneumoniae. PLoS Pathog 8:e1002788. https://doi.org/10.1371/journal.ppat.1002788.

47. Fleurie A, Lesterlin C, Manuse S, Zhao C, Cluzel C, Lavergne J-P, FranzWachtel M, Macek B, Combet C, Kuru E, VanNieuwenhze MS, Brun YV Sherratt D, Grangeasse C. 2014. MapZ marks the division sites and positions FtsZ rings in Streptococcus pneumoniae. Nature 516:259-262. https://doi.org/10.1038/nature13966.

48. Perez AJ, Cesbron Y, Shaw SL, Bazan Villicana J, Tsui H-CT, Boersma MJ, Ye ZA, Tovpeko Y, Dekker C, Holden S, Winkler ME. 2019. Movement dynamics of divisome proteins and PBP2x:FtsW in cells of Streptococcus pneumoniae. Proc Natl Acad Sci U S A 116:3211-3220. https://doi.org/10.1073/ pnas. 1816018116.

49. Fenton AK, El Mortaji L, Lau DTC, Rudner DZ, Bernhardt TG. 2016. CozE is a member of the MreCD complex that directs cell elongation in Streptococcus pneumoniae. Nat Microbiol 2:16237. https://doi.org/10.1038/ nmicrobiol.2016.237

50. Rued BE, Zheng JJ, Mura A, Tsui H-CT, Boersma MJ, Mazny JL, Corona F, Perez AJ, Fadda D, Doubravová L, Buriánková K, Branny P, Massidda O, Winkler ME. 2017. Suppression and synthetic-lethal genetic relationships of $\Delta \mathrm{gpsB}$ mutations indicate that GpsB mediates protein phosphorylation and penicillin-binding protein interactions in Streptococcus pneumoniae D39. Mol Microbiol 103:931-957. https://doi.org/10.1111/mmi.13613.

51. Land AD, Tsui H-CT, Kocaoglu O, Vella SA, Shaw SL, Keen SK, Sham L-T, Carlson EE, Winkler ME. 2013. Requirement of essential Pbp2x and GpsB for septal ring closure in Streptococcus pneumoniae D39. Mol Microbiol 90:939-955. https://doi.org/10.1111/mmi.12408.

52. Holečková N, Doubravová L, Massidda O, Molle V, Buriánková K, Benada O, Kofroňová O, Ulrych A, Branny P. 2014. LocZ is a new cell division protein involved in proper septum placement in Streptococcus pneumoniae. mBio 6:e01700-14. https://doi.org/10.1128/mBio.01700-14.

53. Cleverley RM, Rutter ZJ, Rismondo J, Corona F, Tsui H-CT, Alatawi FA, Daniel RA, Halbedel S, Massidda O, Winkler ME, Lewis RJ. 2019. The cell cycle regulator GpsB functions as cytosolic adaptor for multiple cell wall enzymes. Nat Commun 10:261. https://doi.org/10.1038/s41467-018-08056-2.

54. Zheng JJ, Perez AJ, Tsui H-CT, Massidda O, Winkler ME. 2017. Absence of the $\mathrm{KhpA}$ and $\mathrm{KhpB}$ (JAG/EloR) RNA-binding proteins suppresses the requirement for $\mathrm{PBP} 2 \mathrm{~b}$ by overproduction of FtsA in Streptococcus pneumoniae D39. Mol Microbiol 106:793-814. https://doi.org/10.1111/mmi .13847 
55. Ng W-L, Robertson GT, Kazmierczak KM, Zhao J, Gilmour R, Winkler ME. 2003. Constitutive expression of PcsB suppresses the requirement for the essential VicR (YycF) response regulator in Streptococcus pneumoniae R6. Mol Microbiol 50:1647-1663. https://doi.org/10.1046/j.1365 $-2958.2003 .03806 . x$

56. Boersma MJ, Kuru E, Rittichier JT, VanNieuwenhze MS, Brun YV, Winkler ME. 2015. Minimal peptidoglycan (PG) turnover in wild-type and PG hydrolase and cell division mutants of Streptococcus pneumoniae D39 growing planktonically and in host-relevant biofilms. J Bacteriol 197:3472-3485. https://do .org/10.1128/JB.00541-15.

57. Mascher T, Heintz M, Zähner D, Merai M, Hakenbeck R. 2006. The CiaRH system of Streptococcus pneumoniae prevents lysis during stress induced by treatment with cell wall inhibitors and by mutations in pbp $2 x$ involved in beta-lactam resistance. J Bacteriol 188:1959-1968. https://doi .org/10.1128/JB.188.5.1959-1968.2006.

58. Eldholm V, Gutt B, Johnsborg O, Brückner R, Maurer P, Hakenbeck R, Mascher T, Håvarstein LS. 2010. The pneumococcal cell envelope stresssensing system LiaFSR is activated by murein hydrolases and lipid II-interacting antibiotics. J Bacteriol 192:1761-1773. https://doi.org/10.1128/JB .01489-09.

59. Blanchette-Cain K, Hinojosa CA, Akula Suresh Babu R, Lizcano A, Gonzalez-Juarbe N, Munoz-Almagro C, Sanchez CJ, Bergman MA, Orihuela CJ. 2013. Streptococcus pneumoniae biofilm formation is strain dependent, multifactorial, and associated with reduced invasiveness and immunoreactivity during colonization. mBio 4:e00745-13. https://doi.org/ 10.1128/mBio.00745-13

60. Guenzi E, Gasc AM, Sicard MA, Hakenbeck R. 1994. A two-component signal-transducing system is involved in competence and penicillin susceptibility in laboratory mutants of Streptococcus pneumoniae. Mol Microbiol 12:505-515. https://doi.org/10.1111/j.1365-2958.1994.tb01038.x.

61. Sebert ME, Palmer LM, Rosenberg M, Weiser JN. 2002. Microarray-based identification of htrA, a Streptococcus pneumoniae gene that is regulated by the $\mathrm{CiaRH}$ two-component system and contributes to nasopharyngea colonization. Infect Immun 70:4059-4067. https://doi.org/10.1128/IAI.70 8.4059-4067.2002

62. Vincent HA, Deutscher MP. 2006. Substrate recognition and catalysis by the exoribonuclease RNase R. J Biol Chem 281:29769-29775. https://doi .org/10.1074/jbc.M606744200.

63. Jensch I, Gámez G, Rothe M, Ebert S, Fulde M, Somplatzki D, Bergmann $S$ Petruschka L, Rohde M, Nau R, Hammerschmidt S. 2010. PavB is a surfaceexposed adhesin of Streptococcus pneumoniae contributing to nasopharyngeal colonization and airways infections. Mol Microbiol 77:22-43. https://doi.org/10.1111/j.1365-2958.2010.07189.x.

64. Kwon H-Y, Kim S-W, Choi M-H, Ogunniyi AD, Paton JC, Park S-H, Pyo S-N, Rhee D-K. 2003. Effect of heat shock and mutations in ClpL and ClpP on virulence gene expression in Streptococcus pneumoniae. Infect Immun 71:3757-3765. https://doi.org/10.1128/IAI.71.7.3757-3765.2003.

65. Johnston C, Hauser C, Hermans PWM, Martin B, Polard P, Bootsma HJ, Claverys J-P. 2016. Fine-tuning of choline metabolism is important for pneumococcal colonization. Mol Microbiol 100:972-988. https://doi.org/ 10.1111/mmi.13360

66. Nagai K, Domon $H$, Maekawa T, Oda M, Hiyoshi T, Tamura H, Yonezawa $D$, Arai Y, Yokoji M, Tabeta K, Habuka R, Saitoh A, Yamaguchi M, Kawabata S, Terao Y. 2018. Pneumococcal DNA-binding proteins released through autolysis induce the production of proinflammatory cytokines via Toll-like receptor 4. Cell Immunol 325:14-22. https://doi.org/10.1016/j.cellimm.2018.01 .006 .

67. Zheng JJ, Sinha D, Wayne KJ, Winkler ME. 2016. Physiological roles of the dual phosphate transporter systems in low and high phosphate conditions and in capsule maintenance of Streptococcus pneumoniae D39. Front Cell Infect Microbiol 6:63. https://doi.org/10.3389/fcimb.2016.00063.

68. Merino E, Jensen RA, Yanofsky C. 2008. Evolution of bacterial trp operons and their regulation. Curr Opin Microbiol 11:78-86. https://doi.org/10 .1016/j.mib.2008.02.005

69. Deikus G, Babitzke P, Bechhofer DH. 2004. Recycling of a regulatory protein by degradation of the RNA to which it binds. Proc Natl Acad Sci U S A 101:2747-2751. https://doi.org/10.1073/pnas.0307343101.

70. Lee F, Yanofsky C. 1977. Transcription termination at the trp operon attenuators of Escherichia coli and Salmonella typhimurium: RNA secondary structure and regulation of termination. Proc Natl Acad Sci U S A 74:4365-4369. https://doi.org/10.1073/pnas.74.10.4365.

71. Melior H, Li S, Madhugiri R, Stötzel M, Azarderakhsh S, Barth-Weber S, Baumgardt K, Ziebuhr J, Evguenieva-Hackenberg E. 2019. Transcription attenuation-derived small RNA rnTrpL regulates tryptophan biosynthesis gene expression in trans. Nucleic Acids Res 47:6396-6410. https://doi .org/10.1093/nar/gkz274.

72. DebRoy S, Gebbie M, Ramesh A, Goodson JR, Cruz MR, van Hoof A, Winkler WC, Garsin DA. 2014. A riboswitch-containing sRNA controls gene expression by sequestration of a response regulator. Science 345:937-940. https://doi .org/10.1126/science.1255091.

73. Mellin JR, Koutero M, Dar D, Nahori M-A, Sorek R, Cossart P. 2014. Seques tration of a two-component response regulator by a riboswitch-regulated noncoding RNA. Science 345:940-943. https://doi.org/10.1126/science .1255083 .

74. Deikus G, Bechhofer DH. 2007. Initiation of decay of Bacillus subtilis trp leader RNA. J Biol Chem 282:20238-20244. https://doi.org/10.1074/jbc M702747200.

75. Ramos-Montañez S, Tsui H-CT, Wayne KJ, Morris JL, Peters LE, Zhang F, Kazmierczak KM, Sham L-T, Winkler ME. 2008. Polymorphism and regulation of the spxB (pyruvate oxidase) virulence factor gene by a CBS-HotDog domain protein (SpxR) in serotype 2 Streptococcus pneumoniae. Mol Microbiol 67:729-746. https://doi.org/10.1111/j.1365-2958.2007.06082.x.

76. Kazmierczak KM, Wayne KJ, Rechtsteiner A, Winkler ME. 2009. Roles of rel (Spn) in stringent response, global regulation and virulence of serotype 2 Streptococcus pneumoniae D39. Mol Microbiol 72:590-611. https://doi .org/10.1111/j.1365-2958.2009.06669.x.

77. Sinha D, Zheng JJ, Tsui H-CT, Richardson JD, De Lay NR, Winkler ME. 2020. $\mathrm{S} 1$ domain RNA-binding protein CVfD is a new posttranscriptional regulator that mediates cold sensitivity, phosphate transport, and virulence in Streptococcus pneumoniae D39. J Bacteriol 202:e00245-20. https://doi .org/10.1128/JB.00245-20.

78. Bolger AM, Lohse M, Usadel B. 2014. Trimmomatic: a flexible trimmer for Illumina sequence data. Bioinformatics 30:2114-2120. https://doi.org/10 .1093/bioinformatics/btu170.

79. Langmead B, Salzberg SL. 2012. Fast gapped-read alignment with Bowtie 2. Nat Methods 9:357-359. https://doi.org/10.1038/nmeth.1923.

80. Sinha D, Matz L, Cameron T, De Lay NR. 2018. Poly(A) polymerase is required for RyhB sRNA stability and function in Escherichia coli. RNA 24: 1496-1511. https://doi.org/10.1261/rna.067181.118.

81. Miller JH. 1992. A short course in bacterial genetics. Cold Spring Harbor Laboratory Press, Cold Spring Harbor, NY.

82. Rosch JW, Mann B, Thornton J, Sublett J, Tuomanen E. 2008. Convergence of regulatory networks on the pilus locus of Streptococcus pneumoniae. Infect Immun 76:3187-3196. https://doi.org/10.1128/IAI.00054-08.

83. Gómez-Mejia A, Gámez G, Hirschmann S, Kluger V, Rath H, Böhm S, Voss F, Kakar N, Petruschka L, Völker U, Brückner R, Mäder U, Hammerschmidt S. 2018. Pneumococcal metabolic adaptation and colonization are regulated by the two-component regulatory system 08. mSphere 3:e0016518. https://doi.org/10.1128/mSphere.00165-18.

84. Andreassen PR, Trappetti C, Minhas V, Nielsen FD, Pakula K, Paton JC, Jørgensen MG. 2020. Host-glycan metabolism is regulated by a species-conserved two-component system in Streptococcus pneumoniae. PLoS Pathog 16:e1008332. https://doi.org/10.1371/journal.ppat .1008332.

85. Mascher T, Zähner D, Merai M, Balmelle N, de Saizieu AB, Hakenbeck R 2003. The Streptococcus pneumoniae cia regulon: CiaR target sites and transcription profile analysis. J Bacteriol 185:60-70. https://doi.org/10 $.1128 / \mathrm{JB} .185 .1 .60-70.2003$.

86. Halfmann A, Kovács M, Hakenbeck R, Brückner R. 2007. Identification of the genes directly controlled by the response regulator CiaR in Streptococcus pneumoniae: five out of 15 promoters drive expression of small non-coding RNAs. Mol Microbiol 66:110-126. https://doi.org/10.1111/j.1365-2958.2007 .05900.x.

87. Schnorpfeil A, Kranz M, Kovács M, Kirsch C, Gartmann J, Brunner I, Bittmann S, Brückner R. 2013. Target evaluation of the non-coding csRNAs reveals a link of the two-component regulatory system $\mathrm{CiaRH}$ to competence control in Streptococcus pneumoniae R6. Mol Microbiol 89: 334-349. https://doi.org/10.1111/mmi.12277. 